Türkiye Jeoloji Bülteni
Geological Bulletin of Turkey
$62(2019) 221-246$
doi: $10.25288 /$ tj $b .546135$

\title{
Fethiye Burdur Fay Zonu'nun Kuzeydoğu Kesiminin (Burdur-Güneybatı Anadolu) Göreceli Tektonik Aktivitesinin Jeomorfik İndislerle İncelenmesi
}

Investigation of Relative Tectonic Activity of the Northeastern Part of the Fethiye Burdur Fault Zone (Burdur-Southwestern Anatolia) by Geomorphic Indices

\author{
Berkant Coşkuner $^{* 1} \mathbb{D}$, Yaşar Eren ${ }^{1}$ D, Ramazan Demircioğlu² ${ }^{\mathbb{D}}$, Rahmi Aksoy ${ }^{1}$ (D) \\ ${ }^{1}$ Konya Teknik Üniversitesi, Mühendislik ve Doğa Bilimleri Fakültesi, \\ Jeoloji Mühendisliği Bölümü, Selçuklu, Konya \\ ${ }^{2}$ Aksaray Üniversitesi, Să̆lık Bilimleri Fakültesi, Acil Yardım ve Afet Yönetimi Bölümü, Aksaray
}

Geliş/Received : 28.03.2019 • Düzeltilmiș Metin Geliș/Revised Manuscript Received : 03.07.2019 • Kabul/Accepted : 25.07 .2019 • Bask1/Printed : 31.08 .2019

Öz: Bu çalışmada Burdur güneyinde yer alan Burdur ve Yarışlı havzalarının jeomorfolojik indislerle tektonik aktivitesinin incelenmesi amaçlanmıştır. Yörede Jura- Kretase yaşlı ofiyolitik melanj, Geç Triyas - Erken Jura yaşlı rekristalize kireçtaşları, Geç Miyosen - Erken Pliyosen yaşı killi kireçtaşları ve Geç Pliyosen - Kuvaterner yaşı alüvyal yelpaze çökelleri gibi değişik kökenli kayaçlar bulunmaktadır. İnceleme alanı Fethiye - Burdur Fay Zonu (FBFZ)' nun KD kesimini kapsamaktadır. Tarihsel ve aletsel dönemde birçok deprem olușturan FBFZ bu kesimde, KD-GB uzanımlı Burdur, Karakent, Karacaören fayları ve KB-GD uzanımlı Karaçal Fayı ile temsil edilmektedir. Söz konusu fayların yanı sıra bölgede küçük ölçekli birçok fay bulunmaktadır. Yapılan çalışmada bölgenin tektonik aktvitesini belirlemek için Dağ Yamacı Eğrilik İndisi (Smf), Vadi Taban Genişliği - Vadi Yüksekliği Oranı İndeksi (Vf), Normalleştirilmiş Akarsu Uzunluk - Eğri İndisi (SLK), Asimetri Faktörü (AF), Topografi Simetri Faktörü (T), ve Göreceli Aktif Tektonik İndeksi (Iat) gibi birçok değer hesaplanmıș ve bunlar arazi verileri ile beraberce değerlendirilerek yorumlanmıştır. Elde edilen sonuçlara göre Smf 1,03-1,66, ortalama Vf 0,28-10,85, ortalama SLK 1,84-7,95, T 0-0,6 arasında değișmektedir. Burdur Havzası'na ait AF değeri 60,14 iken alt alanlara ait Iat değerleri ise Sınıf-2 ve Sınıf-3 ü kapsamaktadır. Jeomorfik indisler diğer jeolojik bulguları doğrular şekilde inceleme alanının yüksek ve orta seviyede tektonik bir aktiviteye sahip olduğunu ortaya koymaktadır.

Anahtar Kelimeler: Burdur Havzas1, Fethiye - Burdur Fay Zonu, Iat, jeomorfik indis, SLK.

\begin{abstract}
This study aims to investigate the tectonic activity with geomorphological indices within Burdur and Yarısll Basins in the south of Burdur. The study area consists of Jurassic-Cretaceous ophiolitic melange, Late Triassic-Early Jurassic recrystallized limestone, Late Miocene - Early Pliocene marl and clayed limestone and Late Pliocene-Early Pleistocene alluvial fan deposit. The study area covers the NE section of the Fethiye-Burdur Fault Zone (FBFZ). The FBFZ, which caused many earthquakes in historical and instrumental periods, is represented by NE-SW trending Burdur, Karakent, Karacaören faults and NW-SE trending Karaçal fault. In addition there are many small scale faults in the area. In order to determine the tectonic activity of the region, some geomorphological indices such as Mountain-Front Sinuosity (Smf), Ratio of Valley-Floor Width to Valley Height (Vf), Normalized Stream Length - Gradient Index (SLK), Asymmetry Factor (AF), Topographic Symmetry Factor (T), and Index of relative active tectonics (Iat) were calculated. The obtained data were compared with the field observations. According to the results, Smf ranges between 1.03-1.66, average Vf ranges between 0.28-10.85, average SLK ranges between 1.84-7.95 and Tranges between 0-0.6. The AF value of Burdur Basin is 60,14 whereas the Iat values of subareas cover Class-2 and Class-3. Geomorphic indices, confirming the other geological findings, show that the study area has moderate to high level tectonic activity.
\end{abstract}

Keywords: Burdur Basin, Fethiye - Burdur Fault Zone, Geomorphic indices, Iat, SLK.

*Yazışma / Correspondence: bcoskuner@ktun.edu.tr

(C) 2019 JMO Her hakkı saklıdır/All rights reserved http://tjb.jmo.org.tr http://dergipark.gov.tr/tjb 


\section{GíRiş}

Batı Anadolu, sismik açıdan dünyadaki en aktif kıta içi genişleme ve riftleşmenin başlangıç aşamasını yansıtan tektonik olayların gözlendiği bölgelerden birini oluşturur. Geç Miyosen - Pliyosen'den beri $\mathrm{K}$ - G yönlü gerilme deformasyonunun etkisi altında bulunan bölge (Angelier vd., 1981; Koçyiğit, 1984; Kissel vd., 1985; Şengör, 1987;
Jackson ve McKenzie, 1988; Seyitoğlu ve Scott, 1991; Zanchi vd., 1993; Cohen vd., 1995; Bozkurt, 2001), tektonik olarak güneyden Helen Yay1, güneydoğundan Fethiye Burdur Fay Zonu (FBFZ), kuzeydoğudan Eskişehir Fay Zonu ve kuzeyden Kuzey Anadolu Fayı'nın Güney Marmara kolu tarafindan sinırlanır (Barka ve Reilinger, 1997; Koçyiğit ve Özacar 2003; Yaltırak vd., 2012) (Şekil 1a).

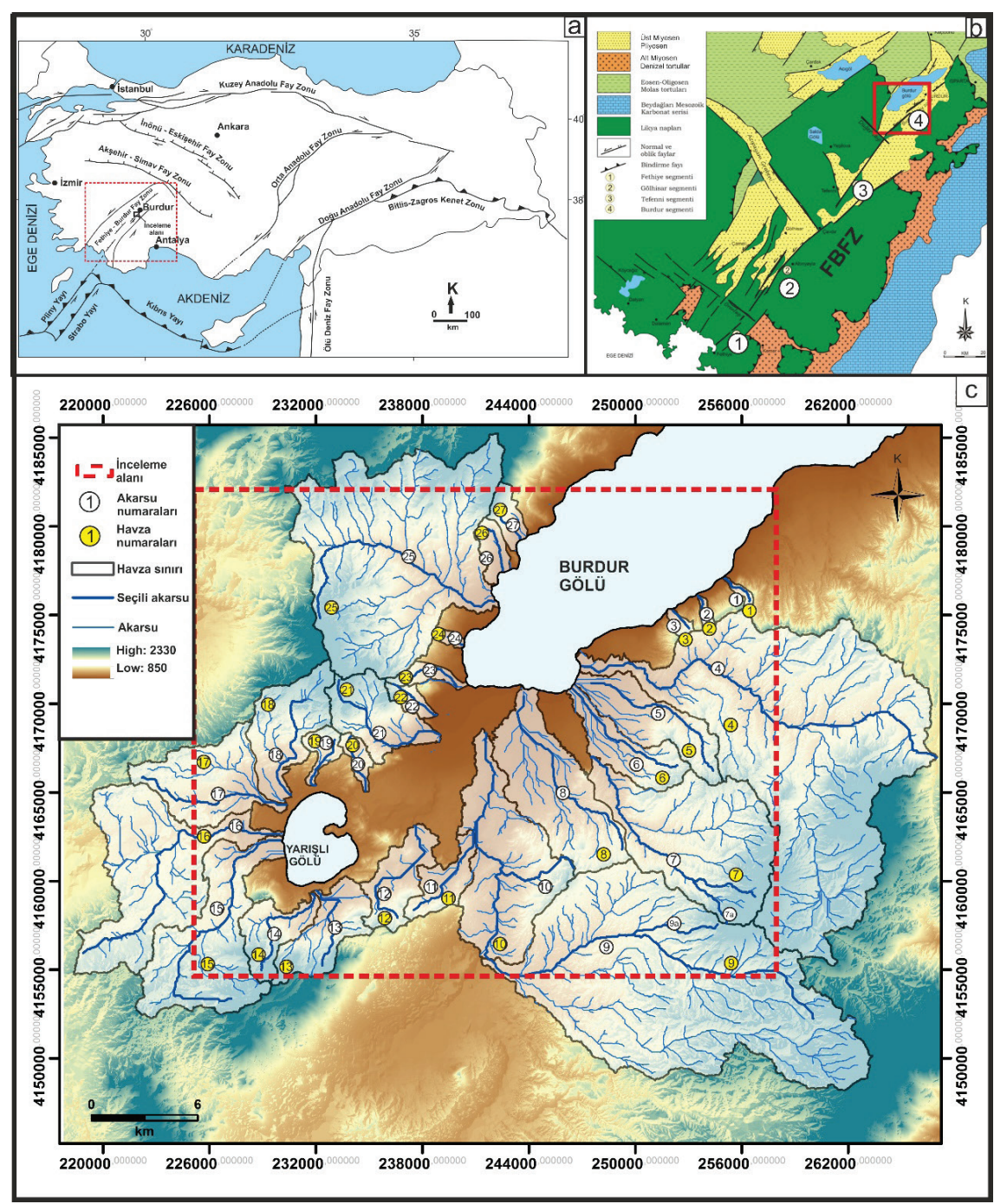

Şekil 1. a) Türkiye ve yakın çevresinin neotektonik yapısı içinde Fethiye - Burdur Fay Zonu (Barka vd., 1995; Yağmurlu, 2000; Yaltırak vd., 2012'den değiştirilerek alınmıştır), b) Fethiye -Burdur Fay Zonu'na ait segmentler (Yağmurlu vd., 2005), c) inceleme alanına ait yer bulduru haritası ve çalışmamızda kullandığımız dereler ve havzalar.

Figure 1. a) Neotectonic structure of Turkey and Fethiye - Burdur Fault Zone modified from (Barka et al. 1995; Yağmurlu, 2000; Yaltırak et al., 2012), b) Segments of the Fethiye - Burdur Fault Zone (Yağmurlu et al., 2005), c) Location map of the study area and streams with basins used in the study. 
FBFZ Batı Anadolu genişleme bölgesi ile Isparta Açısı'nın batı kanadı arasındaki sınırı oluşturur (Barka vd., 1995; Barka ve Reilinger, 1997). Güneybatıda Fethiye Körfezi’nden başayıp kuzeydoğuda Afyon Çay'a kadar uzanan fay zonu yaklaşık $310 \mathrm{~km}$ uzunluğa ve $15-90 \mathrm{~km}$ arasında değişen genişliğe sahiptir (Dumont vd., 1979; Yağmurlu, 2000; Elitez ve Yaltırak, 2014; Hall vd., 2014) (Şekil 1a). Birbirine az çok paralel sol yönlü doğrultu atım bileşenli oblik ve normal faylardan oluşan FBFZ'nun genişliği kuzeydoğudan güneybatıya doğru gittikçe artmaktadır (Hall vd., 2014). Farklı çalışmacılar tarafından farklı bölgeleri çalışılan bu fay zonu Burdur Fethiye Fay1, Fethiye Burdur Fay Zonu, Burdur Fethiye Makaslama Zonu (Dumont vd., 1979; Taymaz ve Price, 1992; Karaman, 1994; Barka vd., 1995; Eyidoğan ve Barka, 1996; Barka ve Reilinger, 1997; Yağmurlu vd., 1997; Ten Veen, 2004; Bozcu vd., 2007; Hall vd., 2009; Elitez ve Yaltırak, 2014) gibi farklı isimler altında incelenmiştir. Bazı araştımacılar FBFZ'nun Kıbrıs Yayı ile Ege Yayı arasındaki sınırı oluşturan Pliny-Strabo Fayının kuzeydoğuya doğru devamı olduğunu ve tek bir fay zonundan oluşmadığını belirtirken (Hall vd., 2014; Elitez vd., 2015, 2016, 2017), bazı çalışmacılar ise sol yönlü doğrultu atım bileşenine sahip bu fay zonunun varlığını sorgulamaktadır (Kaymakci vd., 2014, 2017, 2018; Özkaptan vd., 2014; Alçiçek, 2015). Özkaptan vd., (2018)'e göre FBFZ egemen olarak KBGD yönelimli genişlemeli rejim altında KD-GB doğrultulu normal faylardan oluşmuştur. Doğrultu atım bileşen gösteren normal faylar ise Burdur ve Çameli havzalarının gelişmesini sağlayan transfer faylar olarak yorumlanmıştır. Sol yanal atımlı KD-GB doğrultulu bir deformasyon kuşağı özelliğindeki fay zonu KB-GD faylar ile kesilerek sınırlandırılmış ve kimi araştırıcılar tarafından segmentlere veya bölümlere ayrılmıştır (Yağmurlu vd., 2005; Aksoy ve Aksarı 2016; Özkaptan vd., 2018). Yağmurlu vd., (2005)'e göre bu segmentler GB'dan KD'ya doğru Fethiye segmenti, Gölhisar segmenti, Tefenni segmenti ve Burdur segmentidir (Şekil 1b).

Diğer metodların yanısıra son yı1larda fayların ve aktivitelerinin jeomorfolojik indisler ile incelenmesi de gittikçe yaygınlaşmaktadır (Silva vd., 2003; El Hamdouni vd., 2008; Dehbozorgi vd., 2010; Mahmood ve Gloaguen, 2012; Sarp ve Düzgün, 2012; Yıldırım, 2014; Özkaymak, 2015; Köle, 2016; Cheng vd., 2018; Yazıc1 vd., 2018). Bir bölgenin morfolojisi tektonik hareketlere, kayaçların litolojik özelliklerine, bölgenin iklim koşullarına ve zaman gibi diğer faktörlere bağlı olarak şekillenmektedir (Hack, 1973; Kirby ve Whipple, 2012; Keller ve Pinter, 2002; Duvall vd., 2004; Molin vd., 2004; Whipple, 2004; VanLaningham vd., 2006; Gürbüz vd., 2015). Bu çalışmada da morfometrik indisler kullanılarak üzerinde oldukça tartışma bulunan FBFZ'nun KD kesiminin (Şekil 1b ve c) aktivitesi irdelenmiştir. Segment bariz jeolojik ve morfolojik belirginlikler gösterir ve genç fay aktivitesini yansıtan özelliklere sahiptir. Bölgenin coğrafik hatları genellikle KD-GB yönünde uzanan yükseltiler ve bunlar arasında yer alan vadiler şeklindedir. $\mathrm{Bu}$ morfolojik yapı içerisinde bölgenin en alçak kısmı Burdur Gölü Havzasıdır. Türkiye'nin 7. Büyük gölü olan KD-GB uzanımlı Burdur Gölü 153 km2' lik bir alana sahip olup $842,87 \mathrm{~m}$ rakımlıdır. İnceleme alanının GB' sin da ise $4 \mathrm{~m}$ derinliğinde ve 16 km genişliğinde Yarışlı Gölü bulunmaktadır. Bölgede bulunan akarsular göllere doğru bir akış göstermekte ve bölgenin morfolojik özelliklerini etkilemektedir. Morfolojik yapının yanı sıra Burdur Havzas1 güneydoğudan KD-GB uzanımlı Burdur ve Karacaören fayları, kuzeybatıdan ise Karakent Fayıyla sınırlandırılmıştır. Ayrıca bu fayları dik bir şekilde kesen KB - GD uzanımlı Karaçal Fayı'da bölgenin önemli tektonik yapilarındandir.

Bölgenin tektonik aktivitesini ortaya çıkarmada, ayrıntılı jeolojik incelemelerin yanı sıra jeomorfolojik özelliklerinin de incelenmesi yararlı olacaktır. Bu amaç doğrultusunda bölgenin 
Sayısal Yükseklik Modeli (SYM) oluşturulmuş ve modelden elde edilen sonuçlar ile inceleme alanına ait Normalleştirilmiş Akarsu Uzunluk - Eğri İndisi (SLK), Asimetri Faktörü (Af), Topografi Simetri Faktörü (T), Dă̆ Yamacı Kıvrım indisi (Smf), Vadi Taban Genişliğgi - Vadi Yüksekliği Oranı indisi (Vf) ve Göreceli Aktif Tektonik İndeksi (Iat) hesaplanmış ve elde edilen sonuçlar arazi gözlemleri ile beraber yorumlanmıştır.

\section{JEOLOJIKK ÖZELLIKKLER}

Çalışma alanının temel kayaçlarını Likya Naplarına ait birimler (Graciansky, 1972; Poisson, 1977) oluşturmaktadır. Alanın görünür temelini çoğu serpantinleşmiş ofiyolitik kayaçlar ve bu topluluk içerisinde haritalanabilir kireçtaşı bloklarından yapılı Kızılcadağ Ofiyolitik Melanjı (Poisson, 1977; Şenel vd., 1989; Şenel ve Bölükbaş1, 1997; Moix vd., 2013; Coşkuner, 2017) oluşturmaktadır. Çalışma alanının batı ve güneybatısında geniş alan kaplayan birim, Karakent, Aşağı Müslümler Köyü'nün batısında, Yarışlı Gölü'nün çevresinde, Hacilar Köyü'nün doğusunda ve Karacaören Köyü'nün güneydoğusunda mostra vermektedir (Şekil 2) (Coşkuner, 2017; Coşkuner ve Aksoy, 2017). Kızılcadağ Ofiyolitli Melanj1 serpantinit, peridotit, amfibolit, gabro, bazalt, spilit, piroklastikler ve kumlu - killi çökellerden yapılı matriks içindeki haritalanabilir boyutlara varan kireçtaşı bloklarından oluşmaktadır. Birim üstten Taşkesiği Formasyonu tarafindan bindirme ile örtülmüştür. Taşkesiği Formasyonu'nun gözlenmediği yerlerde ise, Burdur Formasyonu tarafından açılı bir uyumsuzlukla örtülür. Birimin yaşı daha önce yapılan çalışmalara göre Geç Kretase olarak belirlenmiştir (Poisson, 1977; Erakman vd., 1982; Şenel vd., 1989). Bu birim üzerine tektonik olarak Geç Triyas - Erken Jura yaşlı Taşkesiği Formasyonu (Şenel vd., 1989) gelmektedir. Taşkesiği Formasyonu inceleme alanının güneybatı kesiminde genelde Burdur ve Yarışlı Gölü havzalarının kenar kesimlerinde yaygınlık sunmaktadır (Şekil 2). Formasyonun esas litolojisini kalın tabakal1, yer yer masif yap11, gri, pembemsi gri, kirli beyaz renkli kristalize kireçtaşları oluşturur. Kireçtaşları içinde bol megaladon, az miktarda alg, gastropod ve lamelli izlerine rastlanmıştır. Taşkesiği Formasyonu, altta Kızılcadağ Ofiyolitli Melanjı üzerine bindirmekte, üstten ise Geç Miyosen -Pliyosen yaşlı Burdur Formasyonu tarafindan uyumsuz olarak örtülmektedir. Fosil buluntularına göre Geç Triyas - Erken Jura yaşlidır (Poisson, 1977; Karaman, 1986; Şenel vd., 1989).

İnceleme alanının diğer bir kayaç topluluğunu temel kayaçlarını açılı uyumsuz olarak üstleyen Miyosen - Kuvaterner yaşlı örtü birimleri oluşturmaktadır. Örtü kayaçlarının ilk birimini Burdur Formasyonu (Karaman, 1986; Bozcu vd., 2007), inceleme alanının güneydoğusunda Burdur Fayına paralel olarak KD-GB gidişli olarak Suludere, Akyaka, Karaçal, Boğaziçi, İğdeli ve Soğanlı köyleri çevresinde geniş alanlarda mostra verir. Burdur Formasyonu genelde kirli beyaz, krem, sarı ve bej renkli kireçtaşı, marn, kiltaşı ve çamurtaşından oluşmaktadır. Alt düzeylerde kirli beyaz, gri, yeşilimsi gri renkli kiltaşları ile başlar ve üste doğru kirli beyaz, gri renkli, ince tabakalı marnlarla devam eder. Formasyon içinde marnların üzerine karbonat oranının artması ile gri renkli killi kireçtaşları ve kirli beyaz, krem bej renkli orta kalın tabakalı gözenekli kireçtaşları gelir. En üstte ise, kırmızı, kahverenkli kiltaşı, kumtaşı ve konglomera tabakaları bulunur. Tabanda Likya Naplarını açılı uyumsuz olarak örten Burdur Formasyonu üstten Tefenni Formasyonu tarafindan uyumsuz olarak örtülmektedir. 


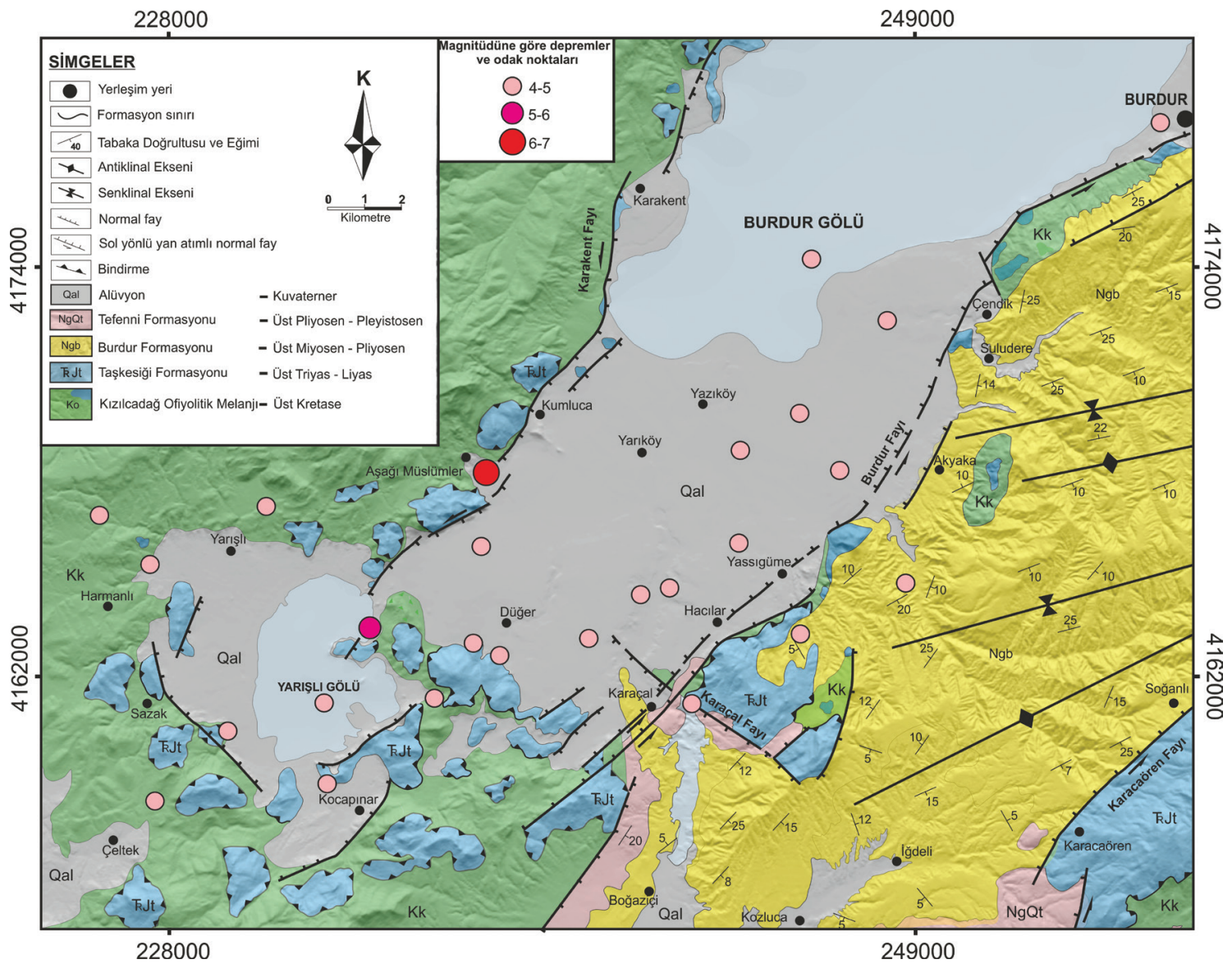

Şekil 2. İnceleme alanının jeoloji haritası (Coşkuner, 2017) ve bölgede 1900'den günümüze kadar oluşmuş 4'ten büyük depremlerin odak noktaları (deprem verileri Kandilli Rasathanesi Deprem Araştırma Enstitüsü ve Birleşik Devletler Jeoloji Araştırmaları (USGS)'den alınmıştır).

Figure 2. Geological map of the study area (Coskuner, 2017) and epicenter of earthquakes larger than 4 in the region from 1900 to the present (earthquake data obtained from Kandilli Observatory and Earthquake Research Institute and United State Geological Survey (USGS).

Önceki çalışmalara göre birimin yaşı Geç Miyosen - Pliyosen olarak kabul edilmiştir (Karaman, 1986; Price, 1989; Alçiçekvd., 2013; Özkaptanvd., 2018). Örtü kayaçlarının ikinci birimini konglomera, kumtaş1, silttaşı ve çamurtaşı ardalanmasından yapılı Tefenni Formasyonu (Aksoy ve Aksarı, 2016) oluşturmaktadır. Formasyonun tabanda kırmızı renkli, kötü boylanmalı, polijenik konglomeralar ile başlar. Bunlar üste doğru kumtaşı ve çamurtaşı ardalanmasına geçer. Birimin yaşı memeli fosillerine ve stratigrafik ilişkilere göre Geç Pliyosen - Pleistosen olarak belirlenmiştir (Alçiçek, 2001; Aksoy ve Aksarı,
2016; Aksarı, 2016). Çalışma alanında en genç oluşukları alttaki tüm birimleri uyumsuz olarak örten kil, silt, kum ve çakıldan oluşan Kuvaterner yaşlı alüvyonlar oluşturur. Alüvyonlar yaygın olarak Burdur Gölü Havzası'nın güneybatısında ve Yarışlı Gölü çevresinde gözlenmektedir (Şekil 2) (Coşkuner, 2017).

FBFZ Burdur segmenti (Yağmurlu vd., 2005) inceleme alanında KD-GB uzanımlı faylar ile bunları dik bir şekilde kesen KB-GD uzanımlı faylardan oluşmaktadır (Şekil 2). Bu faylardan Burdur Havzası'nı GD'dan sinırlayan Burdur Fay1 (Şaroglu vd., 1987; Bozcu vd., 2007) ile 
Karacaören Fayı (Coşkuner, 2017; Coşkuner ve Aksoy, 2017), kuzeybatıdan sinırlayan Karakent Fayı (Emre vd., 2011) ve bunları dik bir şekilde kesen KB-GD uzanımlı Karaçal Fayı (Yağmurlu vd., 2005; Aksar1, 2016; Coşkuner, 2017, Coşkuner ve Aksoy, 2017) inceleme alanının en önemli tektonik unsurlarını oluşturmaktadır. İnceleme alanında yaklaşık $27 \mathrm{~km}$ uzunluk sunan KD-GB gidişli Burdur Fayı, Burdur Havzası'nın güneydoğu kenarını sınırlar. Güneydoğuda Karaçal Köyü'nün 5 km güneyinden başlayıp kuzeydoğuda Burdur şehir merkezine doğru uzanan sol yönlü doğrultu atım bileşenli normal bir faydır. Burdur Fay1 KD ve GB kesimlerinde temel birimleri keserken orta kesimde ise Burdur Formasyonu ile güncel birimler arasındaki sınırı oluşturmaktadır. Karakent Fayı güneyde Yarışlı Gölü'nden başlayıp kuzeyde Karakent kuzeydoğusuna kadar uzanmaktadır ve yaklaşık 19 km uzunluğa sahiptir. KD-GB gidişli ve GD‘ya eğimli sol yanal bileşene sahip normal bir faydır. Karakent Fayı temel birimler ile alüvyonlar arasındaki sınırı oluşturmaktadır. Burdur Havzası'nın GD ucunda bulunan Karacaören Fayı, inceleme alanı içinde Soğanlı Köyü güneyinden başlayıp güneybatıda Karacaören güneyine kadar uzanır. KD-GB doğrultusunda uzanan fay sol yönlü yan atımlı normal bir faydır ve yaklaşı $9 \mathrm{~km}$ uzunluğa sahiptir. Karacaören Fayı Taşkesiği Formasyonu ile Burdur Formasyonu arasında bir sınır hattı olarak gözlenmektedir. İnceleme alanı içinde de Fethiye Burdur Fay Zonu'nun diğer kesimlerinde olduğu gibi (Yağmurlu vd., 2005; Aksoy ve Aksar1, 2016; Coşkuner, 2017; Coşkuner ve Aksoy, 2017) zonun genel gidişine aykırı gelişmiş KB-GD gidişli normal faylar bulunmaktadır. Bunlardan Karaçal Fayı, Karaçal Köyü kuzeyinde yaklaşık 7 km uzunluğunda, GB' ya eğimli normal bir faydır. Karaçal Fayı, Likya Napları ile Burdur ve Tefenni formasyonlarını karşı karşıya getirmiştir. Çalışma alanında daha önce tanımlanan harita ölçeğindeki fayların dışında Yarışlı Gölü ve çevresinde de daha küçük ölçekli faylar bulunmaktadır Bu faylar temel birimler ile güncel birimler arasındaki sınırı oluşturmakta ve Yarışlı Gölü'nü çevrelemektedir (Şekil 2).

Tektonik açıdan oldukça aktif olan FBFZ tarihsel ve aletsel dönem içerisinde birçok deprem oluşturmuş ve bu depremler sonucunda bölgede ciddi can ve mal kayıpları yaşanmıştır. Aletsel dönem içinde oluşan 1914 Burdur, (M=7.1), 1957 Fethiye $(M=7.1), 1964$ Tefenni $(M=5.7)$ ve 1971 Burdur ( $M=6.2)$ (Kandilli rasathanesi) depremleri fay zonu üzerindeki orta ve büyük magnitüdlü depremlere örnektir. İnceleme alanında Kandilli Rasathanesi verilerine göre aletsel dönem içerisinde magnitüdü 4'ten büyük olan depremlerin odak noktaları (Şekil 2) gösterilmiştir.

\section{MATERYAL VE YÖNTEM}

$\mathrm{Bu}$ çalışmada yörenin tektonik aktivitesini jeomorfolojik indisler ile belirlemek amaciyla Dağ Yamacı Eğriliği indisi (Smf), Vadi Taban Genişliği - Vadi Yüksekliği Oranı indisi (Vf), Normalleştirilmiş Akarsu Uzunluk - Eğri İndisi (SLK), Asimetri Faktörü (AF), Topoğrafya Simetri Faktörü (T) (Şekil 3) ve Göreceli Aktif Tektonik İndeksi (Iat) gibi indisler hesaplanmıştır.

Çalışmalarda bölgeye ait 1/25.000 ölçekli topografik haritaların ArcGIS 10.0 ortamında sayısallaştırılması ile elde edilen 10 metre çözünürlüklü SYM (Sayısal Yükseklik Modeli) kullanılmıştır. Oluşturulan SYM ile inceleme alanına ait drenaj ağları ve havza sınırları ArcGIS programı bünyesindeki, ArcHydro Tools kullanılarak belirlenmiştir (Şekil 1c). Farklı bölgelerin tektonik aktivitesini karşılaştırmak için, ortalama SLK ve Vf değerleri kullanılarak her bir havzaya ait Iat değerleri hesaplanmıştır. Ayrıca çalışma alanındaki ana fay kollarına bağlı olarak bölge 3 alt alana ayrılmış ve bu alt alanlarda ortalama SLK, Vf ve Smf değerlerine göre hesaplanan Iat değerleri ile fay kollarının göreceli tektonik aktivitesi incelenmiştir. 


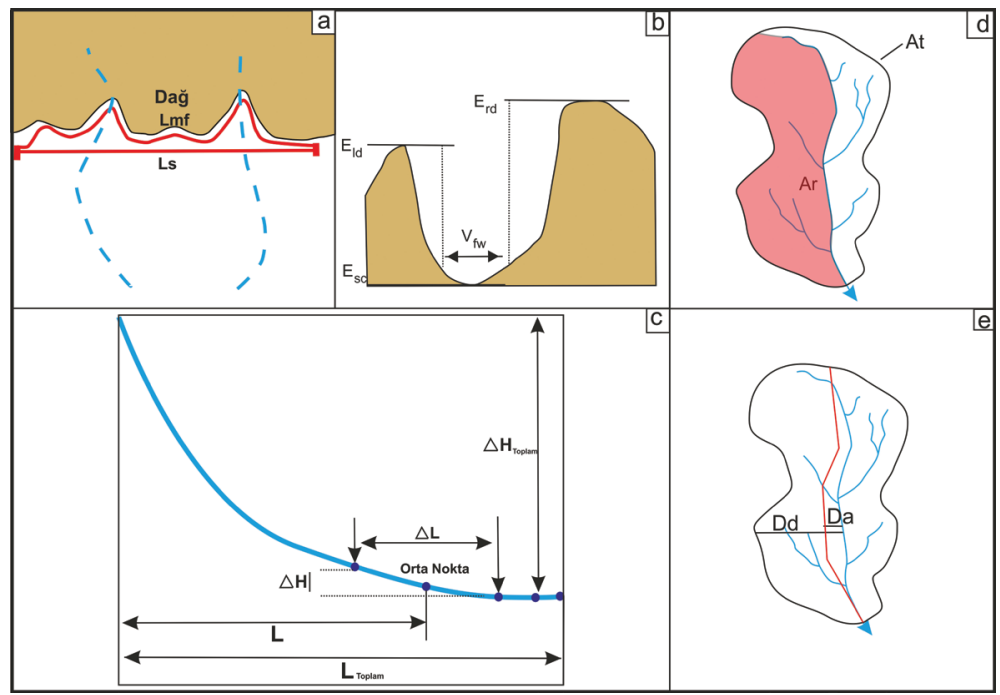

Şekil 3. Bu çalışmada kullanılan jeomorfolojik indisler (Bull ve McFadden, 1977; Cheng vd., 2018)'den değiş̧irilerek alınmıştır. a) Dağ Yamacı Eğrilik indisi (Smf), b) Vadi Taban Genişliği - Vadi Yüksekliği Oranı indisi (Vf), c) Normalleştirilmiş Akarsu Uzunluk - Eğri İndisi (SLK), d) Asimetri Faktörü (AF), e) Topografi Simetri Faktörü (T) (e).

Figure 3. Geomorphic indices applied in this study modified from (Bull and McFadden, 1977; Cheng et al. 2018). a) Mountain-Front Sinuosity (Smf), b) Valley Floor Width-To-Height (Vf), c) Normalized Stream Length-Gradient (SLK), d) Asymmetry Factor (AF), e) Topographic Symmetry Factor (T).

\section{Dă̆ Yamacı Ĕgriliği İndisi (Mountain-Front Sinuosity - Smf)}

Dağ yamacının morfolojik özelliklerini belirlemede ilk kez Bull (1978) tarafindan kullanılmış ve eşitlik (1) deki gibi ifade edilmiştir (Şekil 3a). Bu indeks dağ yamacının morfolojik özelliklerini kullanarak yamacın tektonik aktivitelerden etkilenip etkilenmediği hakkında bilgi vermektedir. Dă̆ yamacının erozyonal olması durumunda sinüzoidal bir görünüme sahip olacağ1 düşünülürken tektonik aktivitelerden etkilenmesi durumunda daha düz bir görüntüye sahip olacağı fikrini esas almıştır.

$\mathrm{Smf}=\mathrm{Lmf} / \mathrm{Ls}$

Smf: Dağ yamac1 eğriliği indisi,

Lmf: Dağ yamacı eğriliğinin uzunluğu,

Ls: Dağ yamacının düz uzunluğu.
Elde edilen Smf değerlerinin düşük olması dağ yamacının tektonik aktivitesinin daha fazla olduğunu, yüksek olması ise dağ yamacının erozyonal olaylardan daha faza etkilendiğini göstermektedir. Bull ve Mcfadden, (1977) Smf değerlerini bölgelerin tektonik aktivitesine göre sınıflamıştır. Buna göre Smf değeri 1,4' ten az ise Sınıf-1 (tektonik aktivitenin yüksek olduğu bölge), 1,4-3 arasında ise Sinıf-2 (tektonik aktivitenin orta seviyede olduğu bölge), 3 ten büyük ise Sinıf-3 (tektonik aktivitenin az olduğu bölge) grubuna düşmektedir.

$\mathrm{Bu}$ çalışmada Smf indisi SYM kullanılarak belirlenmiştir. SYM belirli yüksekliklere ayrılacak şekilde sınıflandırılmış ve dağ yamaçlarını temsil edecek kırılma (keskin değişim) hatları belirlenerek çizilmiştir. Bu hatlardan ArcGIS 10.0. "measure tools" kullanılarak Lmf ve Ls değerleri ölçülmüş ve Smf indisleri hesaplanmıştır. Elde edilen sonuçlar eş yükseklik eğrilerinin kullanılması 
ile belirlenen Smf değerleri ile karşılaştırılarak sağlaması yapılmıştır. Smf değerleri kullanarak havzamızı sınırlayan yükseltilerin tektonizma ile olan ilişkisi incelenmiş ve farklı bölgelerin göreli tektonik aktivitesi ortaya konulmaya çalışılmıştır.

\section{Vadi Taban Genişliği - Vadi Yüksekliği Oranı İndisi (Ratio of Valley-Floor Width to Valley Height - Vf)}

Vf indsi (Bull ve Mcfadden, 1977; Bull, 1978) tarafından vadilerin "V" veya "U" şekilli vadiler olarak ayırmak için kullanmış ve eşitlik (2) deki gibi ifade edilmiştir (Şekil 3b). Yüksek Vf değerleri geniş vadi tabanına sahip tektonik aktivitenin az olduğu "U" şekilli vadileri temsil ederken düşük Vf değerleri ise tektonik aktivitenin yüksek olduğu "V" şekilli vadileri temsil etmektedir (Keller, 1986; Keller ve Pinter, 2002). Vadilerin farklı kesimlerinde hesaplanan Vf değerleri oldukça değişim sunmaktadır. Bu nedenle değişik akarsu kanallarını birbirleri ile karşılaştırmak için, Vf değerlerinin kanal ağzından belirli mesafelerde hesaplanması daha doğru sonuç vermektedir (Ramírez-Herrera, 1998; Silva vd., 2003; Mahmood ve Gloaguen, 2012; Cheng vd., 2018).

$\mathrm{Vf}=2 \mathrm{Vfw} /(($ Eld-Esc $)+($ Erd-Esc $))$

Vf: Vadi taban genişliği - vadi yüksekliği oran1,

Vfw: Vadi tabanı genişliği,

Eld: Vadinin sol üst sınır yüksekliği,

Erd: Vadinin sağ üst sınır yüksekliği,

Esc: Vadi Tabanının yüksekliği.

Farklı araştırmacılar (Silva vd., 2003; El Hamdouni vd., 2008; Dehbozorgi vd., 2010; Köle, 2016; Mahmood ve Gloaguen, 2012) yaptıkları çalışmalar sonucunda elde ettikleri indislere göre Vf değerlerini 3 sınıfa ayırmıştır. Vf indisi 0,5 ten düşük ise Sınıf -1 tektonik aktivitenin fazla olduğu, Vf indisi 1 ile 0,5 arasında ise Sinıf-2 tektonik aktivitenin orta seviyede olduğu ve Vf değeri 1'den fazla ise Sınıf-3 düşük seviyede tektonik aktivitenin olduğu vadiler olarak yorumlanmıştır.

$\mathrm{Bu}$ çalışmada Vf değerleri ana kanal ağızlarından başlamak üzere 1 'er $\mathrm{km}$ aralıklarla hesaplanmıştır. Ayrıca arazi gözlemleri (Coşkuner, 2017) ile belirlenen fayları kesen yan kollardan da aynı şekilde Vf değerleri bulunmuştur. Değerler SYM'den ArcGIS 10.0. programiyla vadilerin topografik profilleri oluşturulmasıyla elde edilmiştir. $\mathrm{Bu}$ sayede gerek havzadaki vadilerin genel yapısı ortaya konmaya çalışılmış gerekse bu vadilerin tektonizma ile olan ilişsisi incelenmiştir.

\section{Normalleştirilmiş Akarsu Uzunluk - Eğri İndisi (Normalized Stream Length - Gradient Index - SLK)}

Akarsu Uzunluk - Eğri İndisi (SL) indeksi ilk kez Hack (1973) tarafindan tanımlanmış ve bir akarsu boyunca yatak eğimindeki değişiklikleri ortaya çıkarmak için kullanılmakta olup eşitlik (3) teki gibi ifade edilmiştir (Şekil 3c).

$\mathrm{SL}=\Delta \mathrm{H} / \Delta \mathrm{L} * \mathrm{~L}$

SL: Akarsu uzunluk - eğri indisi,

$\Delta \mathrm{H}$ : İndisin hesaplandığı yerin yükseklik değişimi, $\Delta \mathrm{L}$ : İndisin hesaplandiğ 1 yerin uzunluğu,

L: İndisin hesaplandığ 1 yerin orta noktasının akarsuyun başlangıç yerine olan mesafesi.

SL değeri akarsu yatağını oluşturan kayaçların litolojisinden, bölgenin iklimden ve tektonizmasına kadar birçok olaydan etkilenir (Hack, 1973; Brookfield, 1998; Azor vd., 2002; Keller ve Pinter, 2002; Font vd., 2010; Gao vd., 2013; Ntokos vd., 2016). Fakat SL değeri büyük oranda akarsu yatağının uzunluğuna bağlı olarak değişmekte bu da farklı uzunluğa sahip akarsu yataklarını karşılaştırmakta sorunlar ortaya çıkarabilmektedir. Bu nedenden dolayı araştırmacılar (Seeber ve Gornitz, 1983; Chen 
vd., 2003; Pérez-Peña vd., 2009; Wu vd., 2014), tarafindan "K" olarak tanımlanan normalleştirme faktörü kullanılarak SL indeksi normalleştirilecek ve SLK (Normalized Stream Length - Gradient Index) değeri eşitlik (4) teki gibi ifade edilecektir (Şekil 3c). SLK indisini tektonizma dişında etkileyecek litoloji, iklim vb. etmenler elimine edildiğinde değerin yüksek çıkması tektonik aktivitenin yüksek olduğunu, değerin düşük çıkması ise tektonik aktivitenin düşük olduğunun göstergesidir.

$\mathrm{SLK}=\mathrm{SL} / \mathrm{K}$

$\mathrm{K}=\mathrm{H}_{\text {toplam }} / \ln \mathrm{L}_{\text {toplam }}$

$\mathrm{K}$ : Normalleştirme faktörü

$\mathrm{H}_{\text {toplam: }}$ : Akarsu yüksekliğindeki toplam değişiklik, $\mathrm{L}_{\text {toplam }}$ : Toplam akarsu uzunluğu.

Yapılan çalışmalarda elde edilen SLK değerleri kendi içinde 3 sınıfa ayrılmıştır (PérezPeña vd., 2009; Cheng vd., 2018) SLK değeri 3,7 den büyük ise Sınıf 1- yüksek tektonik aktiviteli bölge, 2,5 - 3,7 aras1 Sinıf 2- orta tektonik aktiviteli bölge ve 2,5 tan küçük Sınıf 3- düşük tektonik aktiviteli bölge olarak tanımlanmıştır.

$\mathrm{Bu}$ çalışmada SLK indislerini belirlemek için SYM kullanılmıştır. ArcHydro Tools ile SYM'den belirlenen drenaj ağlarına ait akarsu profilleri oluşturulmuş ve bunlardan SL değerleri hesaplanmıştır. Hesapalanan SL değerlerine ait profiller çizilmiş ve akarsu profillerinden hesaplanan K değerlerine bölünerek SLK değeri elde edilmiştir. Elde edilen SLK değerlerine ait ortalamalar hem havza bazlı hem de fayların göreli tektonik aktivitesini ortaya çıkarmada kullanmıştır.

\section{Asimetri Faktörü (Asymmetry Factor - AF)}

Asimetri Faktörü (AF) bir bölgede tektonik yükselime veya bölgenin litolojisine bağl1 olarak gelişen asimetrinin olup olmadığını belirlemek amacıyla yaygın bir şekilde kullanılır. (Hare ve Gardner, 1985; Keller ve Pinter, 2002) ve eşitlik (5) teki gibi ifade edilir (Şekil 3d). Havzada herhangi bir yükselimin olmadığ 1 durumlarda AF değeri 50 ye yaklaşır ve havzanın simetrik bir özellik gösterdiğini ifade eder. Fakat havzanın tektonik olarak aktif olması veya litoloji farklı1ığ gibi durumlarda bu değer 50 den farklılaşır ve havzanın asimetrik bir yapı kazandığını belirtir.

$\mathrm{AF}=(\mathrm{Ar} / \mathrm{At}) * 100$

AF: Asimetri faktörü,

Ar: Dere akış yönüne göre havzanın sağ tarafında kalan alan,

At: Havzanın toplam alanı

Yapılan çalışmalarda (Bagha vd., 2014; Cheng vd., 2018; Dehbozorgi vd., 2010; El Hamdouni vd., 2008; Köle, 2016; Selim vd., 2013; Xue vd., 2017) AF değerleri 3 sınıfa ayrılmıştır. Buna göre AF indisini mutlak değer içinde 50'den çıkardığımızda sonuç 15 ve daha fazla ise Sınıf-1 tektonik aktivitenin yüksek olduğu ve yüksek oranda eğimlendiği (tilt) bölge, 7 ile 15 arasında ise Sınıf-2 tektonik aktivitenin orta seviyede olduğu ve orta seviyede eğimlendiği bölge, 7'den küçük ise Sınıf-3 tektonik aktivitenin az olduğu ve düşük derecede eğimlendiği bölge olarak yorumlanır.

$\mathrm{Bu}$ çalışmada Burdur Havzası'nın çalışma alanı içerisinde kalan kesimi için AF indisi hesaplanmıştır. Bu sayede havzayı sınırlandıran Burdur ve Karakent faylarının havza üzerindeki etkisi araştırılmıştır. $\mathrm{Bu}$ amaç doğrultusunda ArcHydro Tools ile havza sınırları belirlenmiş ve ArcGIS 10.0. ile havzanın alanı ve dere akış yönünün sağ tarafında kalan alan hesaplanarak AF değeri elde edilmiştir.

\section{Topografi simetri faktörü (Topographic Symmetry Factor - T)}

İlk kez Cox (1994) tarafindan havza asimetrisini değerlendirmek için kullanılan diğer bir yöntem 
olarak belirlenmiş ve eşitlik (6) daki gibi ifade edilmiştir (Şekil 3e). 0 ile 1 arasında değişim gösteren $\mathrm{T}$ değeri asimetrinin artması ile beraber 1'e yaklaşırken asimetrinin azalması ile beraber değer 0'a yaklaşır. Bu sayede inceleme alanında hangi bölgenin daha fazla asimetriye sahip olduğu ortaya çıkar. $\mathrm{Bu}$ asimetri bölgenin tektonik aktivitelerden dolayı yükseldiğini veya bölgedeki litoloji farklılı̆̆ına göre bölgenin asimetri kazandı ğını belirtir.

$\mathrm{T}=\mathrm{D}_{\mathrm{a}} / \mathrm{D}_{\mathrm{d}}$

$\mathrm{T}$ : Topografi simetri faktörü,

$\mathrm{D}_{\mathrm{a}}$ : Havzanın orta çizgisinin drenaj orta çizgisine olan uzaklığı,

$\mathrm{D}_{\mathrm{d}}$ : Havzanın orta çizgisinin havza ayrım çizgisine olan uzaklığı.

Burdur Havzası'na ait simetrinin havzanın neresinde daha az neresinde daha fazla olduğunu belirlemek için bu yöntem kullanılmıştır. ArcGIS 10.0 programı ile birlikte kullanılan Polygon to_Centerline (Dilts, 2015) modülü kullanılarak havzanın orta çizgisi ortaya çıkarılmış ve havzanın GB-KD doğrultusu boyunca $1,5 \mathrm{~km}$ aralıklar ile T değeri hesaplanmıştır.

\section{Göreceli Aktif Tektonik İndeksi (Index of Relative Active Tectonics-Iat)}

Güncel tektonik aktiviteyi göstermek ve bölgeler arası tektonik aktiviteyi kıyaslamak için kullanılmakta ve eşitlik (8) deki gibi ifade edilmektedir (Bull ve Mcfadden, 1977). Önceki çalışmacılar elde ettikleri farklı bölgelerde buldukları benzer indisleri bir araya getirerek hangi bölgenin daha fazla tektonik aktiviteye sahip olduğunu belirlemek için bu indisi kullanmışlardır.

Iat $=\mathrm{S} / \mathrm{n}$

Iat: Göreceli Aktif Tektonik İndeksi,

S: Her bir indisten elde edilen sınıfsal değer,

n: Kullanılan indis sayısı.
El Hamdouni vd., (2008) ve Cheng vd., (2018) elde ettikleri bu değeri 4 sınıfa değerlendirmişlerdir. Buna göre değer 1-1,5 arasinda ise Sinif-1 tektonik aktivitenin çok fazla olduğu bölge, 1,5 ile 2 arasında ise Sınıf-2 tektonik aktivitenin yüksek olduğu bölge, 2-2,5 arasında ise Sinıf-3 tektonik aktivitenin orta seviyede olduğu bölge, 2,5 ile 3 arasında ise Sınıf-4 tektonik aktivitenin az olduğu bölge olarak belirlenmiştir.

Hesaplanan Iat indisi havzaların ve alt alanların tektonik aktivitelerini kıyaslamak için kullanılmıştır. $\mathrm{Bu}$ amaçla Iat indisi havzalarda ortalama SLK ve Vf ve alt alanlarda ortalama SLK, Vf ve Smf değerleri ile oluşturulmuştur.

\section{JEOMORFIK INDIS ANALIZLERİ}

İnceleme alanında faylar tarafından kesilen dağ yamaçlarından Smf değerleri, Burdur Havzası'nın inceleme alanı içerisinde kalan alanlarda ise AF ve T değerleri hesaplanmıştır. Ayrıca morfometrik analizler yapmak için yöre 27 havzaya ayrılmış ve bu havzaya ait ana kanallar gösterilmiştir (Şekil 1c). Bu havzalara ait ana kollardan ve arazi çalışmalarında belirlenen fayları (Coşkuner, 2017, Coşkuner ve Aksoy 2017) kesen yan kollardan SLK ve Vf değerleri hesaplanmıştır.

\section{Dağ Yamacı Eğriliği İndisi (Mountain-Front Sinuosity - Smf)}

İnceleme alanında havzaları sınırlayan dağlardan 21 adet Smf değeri hesaplanmıştır (Şekil 4). Hesaplanan bu Smf değerlerinden 1-2-3-4-5-6-89-10 ve 11 numaralı Smf değerleri Burdur Fayı'na, 7 numaralı Smf değeri Karaçal Fayı'na, 18-19-20 ve 21 numaralı Smf değerleri Karakent Fayı'na, 12-13-14-15 ve 16 numaralı Smf değerleri ise Yarışlı Gölü etrafındaki faylara aittir (Çizelge 1). En yüksek Smf değeri 1,66 ile Burdur Fay1 üzerinde bulunan 3 numaralı $\mathrm{Smf}$ değeri iken en düşük Smf değeri 1,02 ile ana Burdur Fayı'na paralel bir fay bölümüne düşmektedir. Oldukça 
aktif olan Burdur Fayı üzerindeki 3 numaralı Smf değerinin fayın diğer kesimlerindeki değerlere göre daha yüksek çıkmasının nedeni büyük bir olasılıkla litolojiye bağlıdır. $\mathrm{Bu}$ kesimde Burdur Fayı ile Kuvaterner yaşlı alüvyonlar ile Miyo-Pliyosen yaşlı dayanımsız kayaçlardan oluşan Burdur Formasyonu yan yana gelmiştir. En düşük Smf değerleri ise fay boyunca taban bloğunda Mesozoyik Taşkesiği Formasyonu'na ilişkin kireçtaşlarının yaygın olduğu yerde gözlenmektedir. Burdur fayına ait ortalama Smf değeri 1,27 olarak belirlenmiştir. Karaçal Fayındaki Smf değeri ise 1,54 tür. KarakentFayı'nda en düşük değer 1,07 ile 18 nolu iken en yüksek değer 1,14 ile 19 nolu kesimde ölçülmüştür. Bu kesimde tüm Smf değerleri tektonik aktivitesi yüksek faylara özgü düşük değerler vermektedir. Ancak en düşük Smf değeri yine Taşkesiği Formayonu'nun fayı sınırladığ1 yerde elde edilmiştir. Bu kesimdeki ortalama Smf değeri 1,12 olarak belirlenmiştir. Yarışlı Gölü çevresindeki en yüksek Smf değeri 1,34 ile 14 numaralı en düşük değer ise 1,03 ile 15 numaralı değerdir. Bu kesimdeki en yüksek Smf değeri Ofiyolitik Melanj ile Kuvaterner yaşlı kayaçların dokanağında gözlenmiştir. Ortalama Smf değeri ise 1,19 olarak belirlenmiştir.

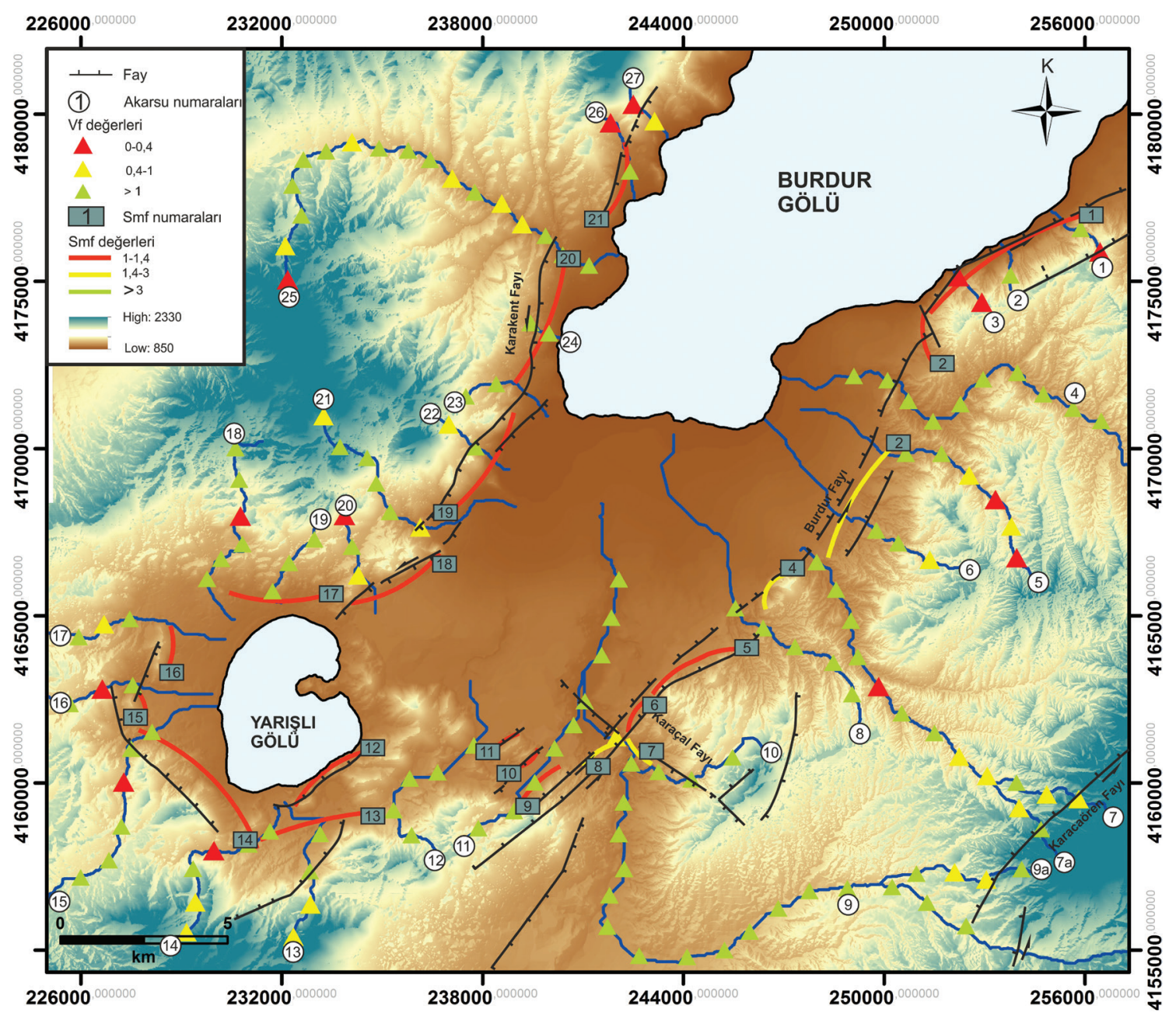

Şekil 4. İnceleme alanına ait faylar, Smf ve Vf değerleri.

Figure 4. Faults, Smf and Vf values within the study area. 
Çizelge 1. İnceleme alanında belirlenen Smf değerleri (Lmf: Dağ yamacı eğriliği uzunluğu; Ls: Dağ yamacı düz uzunluğu; Smf: Dağ yamacı eğriliği indeksi).

Table 1. Smf values within study area. (Lmf: Mountain front length along the foot of the mountain; Ls: The length of the straight line of the mountain front; Smf: Mountain front sinuosity index).

\begin{tabular}{cccc}
\hline No & Lmf $\mathbf{( k m )}$ & Ls $(\mathbf{k m})$ & Smf \\
\hline 1 & 6,44 & 5,34 & 1,20 \\
2 & 1,52 & 1,41 & 1,07 \\
3 & 7,23 & 4,33 & 1,66 \\
4 & 2,04 & 1,4 & 1,45 \\
5 & 3,52 & 3,09 & 1,13 \\
6 & 1,43 & 1,2 & 1,19 \\
7 & 1,85 & 1,2 & 1,54 \\
8 & 2 & 1,39 & 1,43 \\
9 & 1,75 & 1,62 & 1,08 \\
10 & 0,85 & 0,78 & 1,08 \\
11 & 1,06 & 1,03 & 1,02 \\
12 & 2,49 & 2,24 & 1,11 \\
13 & 2,89 & 2,5 & 1,15 \\
14 & 7,2 & 5,35 & 1,34 \\
15 & 1,13 & 1,09 & 1,03 \\
16 & 1,84 & 1,61 & 1,14 \\
17 & 3,96 & 3,08 & 1,28 \\
18 & 3,31 & 3,09 & 1,07 \\
19 & 3,71 & 3,24 & 1,14 \\
20 & 5,18 & 4,6 & 1,12 \\
21 & 2,52 & 2,27 & 1,11 \\
\hline & & &
\end{tabular}

Ortalama Smf değerlerine göre inceleme alanındaki Burdur, Karakent ve Yarışlı Gölü etrafındaki faylar Sınıf-1 grubu değerleri içerisine düşmekte olup, bölgenin tektonik olarak yüksek derecede aktif olduğunu göstermektedir. En düşük ortalama Smf değeri ise 1,12 ile Karakent Fayı'nın olduğu bölümde elde edilmiştir. Ancak Burdur Fayı'nın yüksek Smf değerleri elde edilen ve büyük bir olas1lıkla litolojik farkl111ktan kaynaklanan 3,4 ve 8 nolu değerler hariç tutulduğunda Burdur,
Karakent ve Yarışlı Gölü etrafındaki faylara ait Smf değerleri yaklaşık aynı değeri vermektedir. Diğer bir deyişle ortalama Smf değerlerine göre faylar aynı tektonik aktiviteye sahiptirler. Karaçal Fayı'ndaki yüksek Smf değeri ise bu fayın diğer faylara göre tektonik aktivitesinin daha düşük olmasından kaynaklanmış olmalıdır.

\section{Vadi Taban Genişliği - Vadi Yüksekliği Oranı İndisi (Ratio of Valley-Floor Width to Valley Height - Vf)}

İnceleme alanını çevreleyen 27 adet havzadan 27 adet ana ve 2 adet yankola ait Vf indisleri hesaplanmıştır (Şekil 4). 27 adet havzaya ait en düşük ortalama Vf değeri 0,28 ile 3 numaralı havzadan, en yüksek ortalama Vf değeri 10,85 ile 9 numaralı havzadan elde edilmiştir (Çizelge 2). En düşük değerlerin elde edildiği 3 numaralı havza Burdur Fayı'nın KD kesimindedir ve vadi ofiyolitik melanj içerisinde gelişmiştir. Yine 27 numaralı havzada Karakent Fayı'nın KD kesiminde ofiyolitik melanj içerisinde bulunmaktadır. En yükssek değerlerin yer aldığ 19 numaralı havza da kolaylıkla erozyona uğryabilen Burdur Formasyonu ve tutturulmamış güncel alüvyonlar yaygınlık sunmaktadır. Benzer yüksek değerler 4 nolu $(5,94)$, 6 nolu $(4,71), 11$ nolu $(4,33) 12$ nolu $(4,77)$ ve 26 nolu $(4,63)$ havzalarda da gözlenmektedir. İnceleme alanındaki bireysel akarsu kanallarına ait Vf değerleri incelendiğinde $5,7,14,15,16$ ve 18 numaralı vadiler "U" dan "V" şekilli vadilere geçiş göstermektedir. 15 ve 16 numaralı ana kanallarındaki bu değişim direk fayın kestiği yerlerde 14 numaralı ana kanaldaki değişim ise fayın yakın çevresinde bulunmakta ve bize tektonizmanın vadi şekilleri üzerindeki etkisini göstermektedir. Diğer kanallardaki değişim ise tektonik hareketlerin yanı sıra litoloji ve diğer jeomorfolojik süreçlere bağlı olarak gelişmiş olabilir. 
Çizelge 2. Akarsulara göre ortalama Vf, SLK ve Iat değerleri (Ort. Vf.: Ortalama vadi taban genişliği Vadi yüksekliği oranı indeksi; Ort. SLK: Ortalama normalleştirilmiş akarsu uzunluk - eğri indeksi; Iat: Göreceli aktif tektonik indeksi).

Table 2. Mean Vf, SLK and Iat values according to streams (Ort. Vf.: Mean Vf.-Mean ratio of valley floor width to valley height index; Ort. SLK: Mean SLK-Mean normalized stream length-gradient index; Iat:Index of relative active tectonics).

\begin{tabular}{|c|c|c|c|c|}
\hline $\begin{array}{c}\text { Havza } \\
\text { No. } \\
\end{array}$ & $\begin{array}{c}\text { Akarsu } \\
\text { No. } \\
\end{array}$ & $\begin{array}{c}\text { Ort. } \\
\text { Vf }\end{array}$ & $\begin{array}{l}\text { Ort. } \\
\text { SLK } \\
\end{array}$ & Iat \\
\hline 1 & 1 & 1,01 & 3,98 & 2 (Sinıf-3) \\
\hline 2 & 2 & 1,81 & 3,64 & 2,5 (Sinif-4) \\
\hline 3 & 3 & 0,28 & 3,64 & $1,5($ Sinıf- 2$)$ \\
\hline 4 & 4 & 5,94 & 7,95 & 2 (Sinif-3) \\
\hline 5 & 5 & 2,25 & 3,31 & 2,5 (Sinif-4) \\
\hline 6 & 6 & 4,71 & 2,69 & 2,5 (Sinıf-4) \\
\hline \multirow{2}{*}{7} & 7 & 2,62 & 2,35 & \multirow{2}{*}{2,5 (Sinıf-4) } \\
\hline & $7 \mathrm{a}$ & 1,17 & 3,55 & \\
\hline 8 & 8 & 2,49 & 3,01 & 2,5 (Sinif-4) \\
\hline \multirow{2}{*}{9} & 9 & 10,85 & 3,71 & \multirow{2}{*}{2,5 (Sinıf-4) } \\
\hline & $9 a$ & 1,08 & 3,05 & \\
\hline 10 & 10 & 1,91 & 3,42 & 2,5 (Sinıf-4) \\
\hline 11 & 11 & 4,33 & 2,69 & $2,5($ Sinif-4) \\
\hline 12 & 12 & 4,77 & 2,45 & 3 (Sinıf-4) \\
\hline 13 & 13 & 3,89 & 3,8 & 2 (Sinıf-4) \\
\hline 14 & 14 & 3,0 & 3,58 & 2,5 (Sinıf-4) \\
\hline 15 & 15 & 3,02 & 4,55 & 2 (Sinıf-3) \\
\hline 16 & 16 & 3,11 & 2,89 & 2,5 (Sinif-4) \\
\hline 17 & 17 & 4,16 & 3,94 & 2 (Sinıf-3) \\
\hline 18 & 18 & 4,1 & 3,33 & $2,5(\operatorname{Sin} 1 f-4)$ \\
\hline 19 & 19 & 3,48 & 3,31 & 2,5 (Sinif-4) \\
\hline 20 & 20 & 2,88 & 3,41 & 2,5 (Sinıf-4) \\
\hline 21 & 21 & 2,37 & 2,98 & 2,5 (Sinıf-4) \\
\hline 22 & 22 & 1,22 & 3,49 & $2,5(\operatorname{Sin} 1 f-4)$ \\
\hline 23 & 23 & 1,66 & 3,26 & $2,5(\operatorname{Sin} 1 f-4)$ \\
\hline 24 & 24 & 2,78 & 1,84 & 3 (Sinıf-4) \\
\hline 25 & 25 & 3,56 & 3,14 & $2,5(\operatorname{Sin} 1 f-4)$ \\
\hline 26 & 26 & 4,63 & 2,92 & 2,5 (Sinıf-4) \\
\hline 27 & 27 & 0,48 & 3,53 & 1,5 (Sinif-2) \\
\hline
\end{tabular}

Vf değerleri genel olarak incelendiğinde, Burdur Fayı'nın yer aldığı 1.alt alana düşen bölgede (Şekil 5) ortalama Vf değeri 5,20 Yarışlı Gölü çevresindeki 2. alt alanda ortalama Vf değeri 3,51, Karakent Fayı'nın yer aldığı 3. alt alanda ise ortalama Vf değeri 3,13 olarak belirlenmiştir (Çizelge 3). Her üç alt alanda da Vf değerleri Sınıf 3 tektonik aktivitenin düşük olduğu bölgelere has değerler sunmaktadır (Çizelge 3). Ayrıca Burdur Fayı'nın yer aldığ 1 1.bölgede daha çok Miyosen Kuvaterner yaşlı kolaylıkla erozyona uğrayabilen birimler yaygınlık sunarken Karakent Fayı'nın geçtiği bölgelerde ofiyolitik melanj ve mesozoyik kireçtaşları yer almaktadır. Burdur Fayı'nın geçtiği 1.alt alandaki Vf değerinin 3. alt alandaki değerlere göre daha yüksek olması büyük bir olasılıkla litolojik faktörlere bağlıdır.

\section{Normalleştirilmiş Akarsu Uzunluk - Eğri Indisi (Normalized Stream Length - Gradient Index - SLK)}

İnceleme alanında 27 adet akarsuya ait SL indeksleri hesaplanarak profilleri oluşturulmuştur (Şekil 6). Akarsu profillerindeki ani değişimler SL değerlerinde anomalilere neden olmuştur. $\mathrm{Bu}$ durum 1, 2, 7a, 11, 14, 15, 16 ve 18 numaral profillerde bariz bir şekilde gözlenmektedir (Şekil 6).

Çalışma alanında havzalara ait ana kanalların SL değerlerinin birbirleri ile daha doğru bir şekilde kıyaslanması için, her bir anakanala ait normalleştirme faktörü $(\mathrm{K})$ hesaplanmış ve bunlardan SLK değerleri saptanmıştır (Şekil 7). 


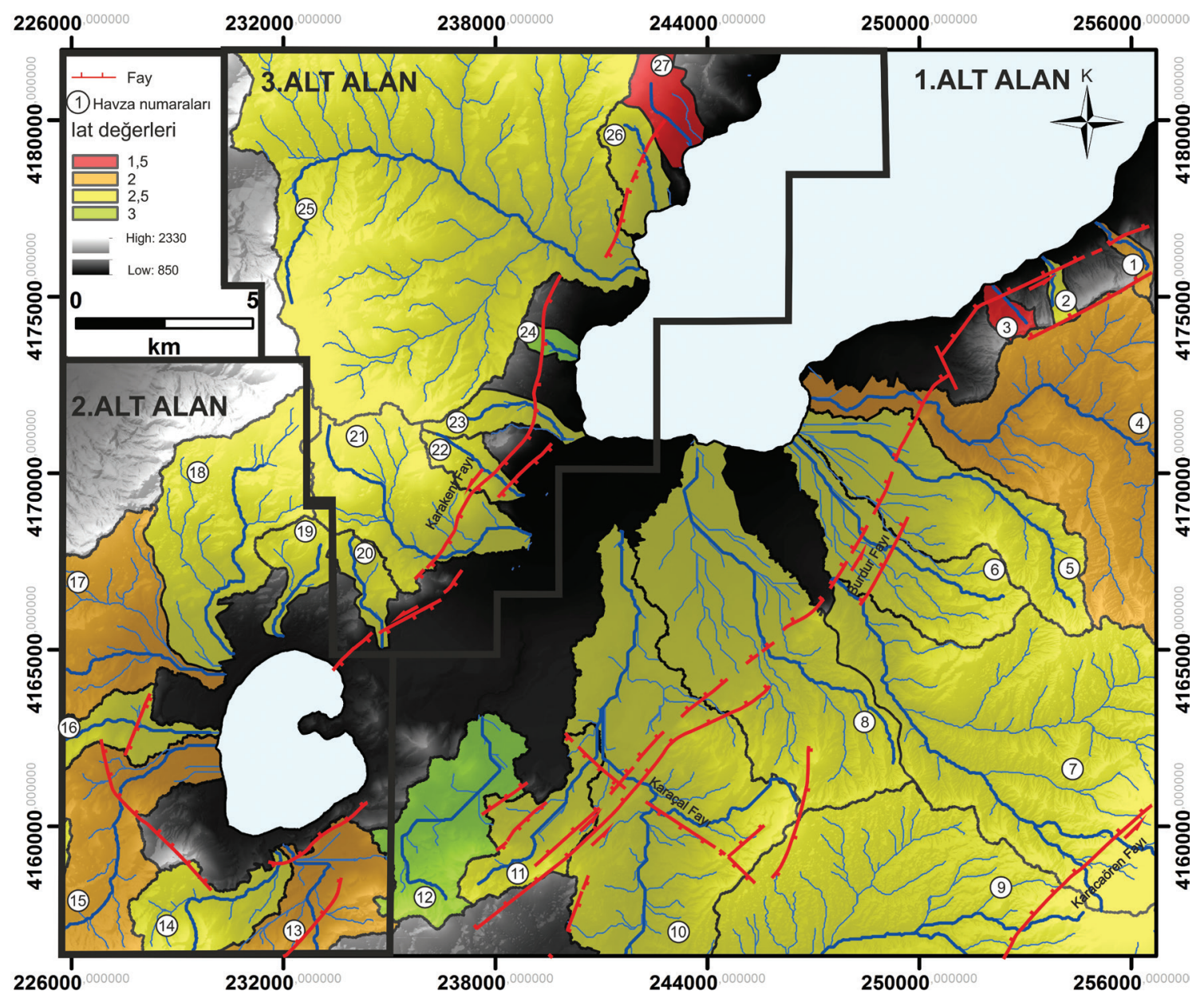

Şekil 5. İnceleme alanında bulunan havzalara ait Iat değerleri ve alt alanlar.

Figure 5. Basins with Iat index and sub areas of study area.

Çizelge 3. İnceleme alanında belirlenen alt alanlara ait ortalama Smf, Vf, SLK değerleri ve bunlardan elde edilen Iat değeri (Ort. Smf: Ortalama dağ yamacı eğriliği indisi; Ort. Vf: Ortalama vadi taban genişliği - vadi yüksekliği oranı indisi; Ort. SLK: ortalama normalleştirilmiş akarsu uzunluk - eğri indisi; Iat: Göreceli aktif tektonik indisi).

Table 3. Mean Smf, Vf and SLK values obtained from the sub-areas determined in the study area and calculated Iat values (Ort. Smf: Mean Smf-Mean mountain front sinuosity index; Ort. Vf: Mean Vf-Mean ratio of valley floor width to valley height index; Ort. SLK: Mean SLK-Mean normalized stream length-gradient index).

\begin{tabular}{lcccc}
\hline Alt Alanlar & Ort. Smf & Ort. Vf & Ort. SLK & Iat \\
\hline 1. Alt Alan & $1,27($ Sinıf-1) & $5,20($ Sinıf-3) & $3,53($ Sinıf- $)$ & $2($ Sinıf-3) \\
2. Alt Alan & $1,19($ Sinıf-1) & $3,51($ Sinıf-3) & $3,72($ Sinıf- $)$ & $1,66($ Sinıf-2) \\
3. Alt Alan & $1,12($ Sinıf-1) & $3,13($ Sinıf-3) & $3,13($ Sinıf-2) & 2 (Sinıf-3) \\
\hline
\end{tabular}




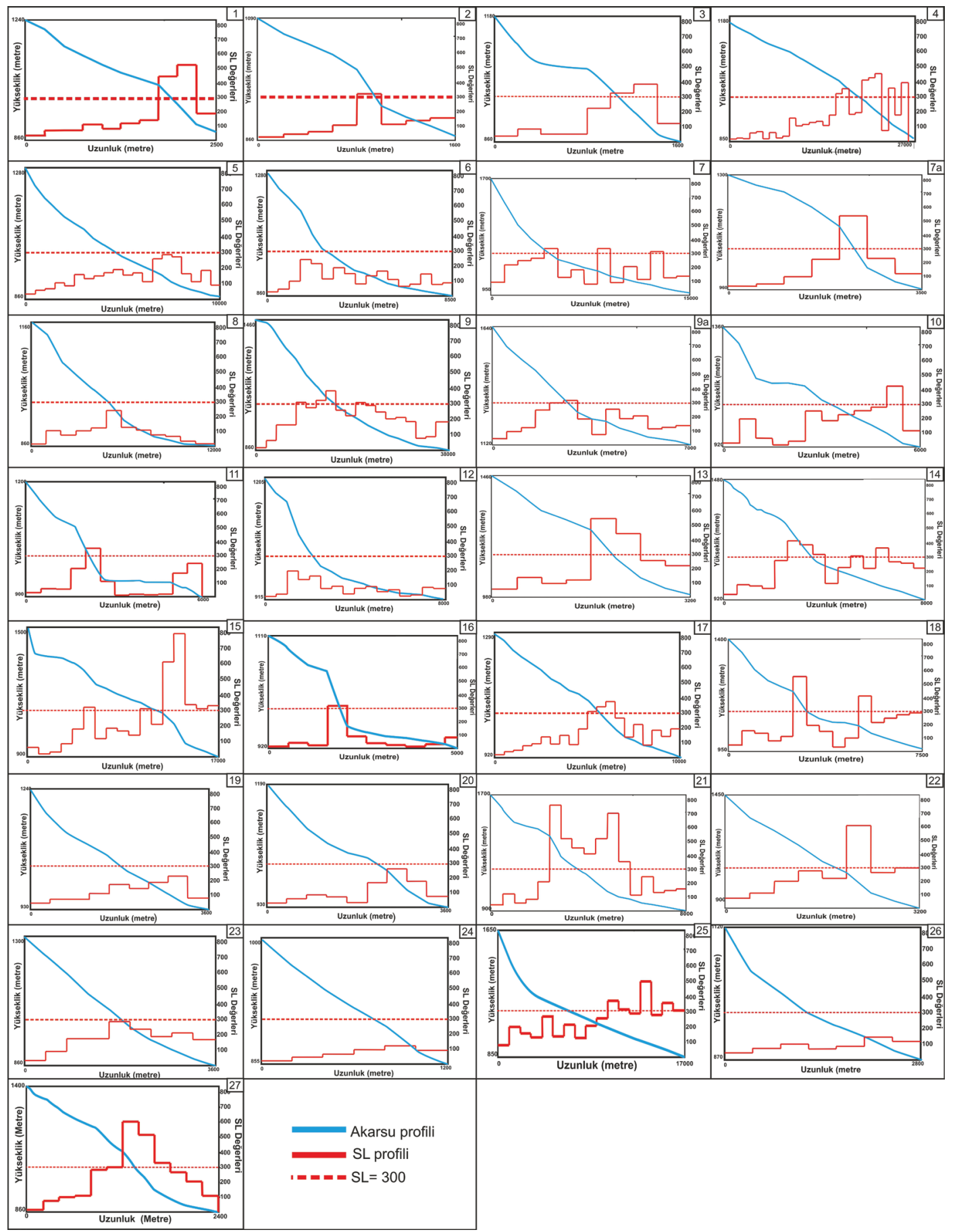

Şekil 6. İnceleme alanında belirlenen derelere ait SL profilleri.

Figure 6. SL profiles which are created from selected rivers at the study area. 


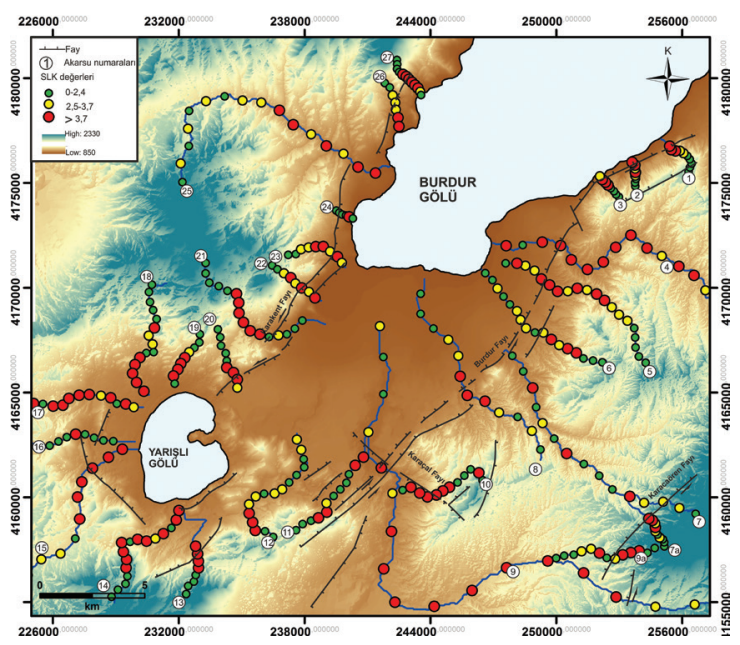

Şekil 7. İnceleme alanına ait SLK değerleri.

Figure 7. SLK values within the study area.

Elde edilen SLK değerlerinin tüm alan içerisinde değişimini de görmek için kontur haritası oluşturulmuştur (Şekil 8).

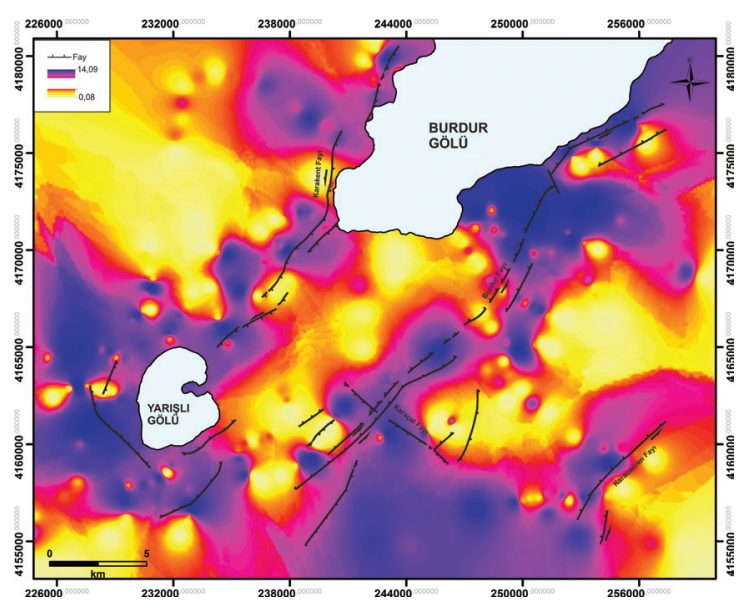

Şekil 8. SLK değerlerinin kontur haritası.

Figure 8. Contour map with SLK values.

SLK değerlerine ait kontur haritas1 incelendiğinde Burdur Fayı boyunca, Karaçal ve Karacaören Fayı üzerinde, Karakent Fayı'nın KD ve GB'sında ve Yarışlı Gölü çevresinde anomaliler izlenmektedir. Elde edilen değerlerin bir çizgisellik oluşturduğu ve bunların faylar ile uyum içerisinde bulunduğu gözlenmiştir (Şekil 8). Dolayısıyla bu bölgelerdeki anomalilerin ana olarak tektonik haraketlere bağlı olarak geliştiği görülmektedir. Bununla beraber inceleme alanının batı kesimlerinde 25 nolu havzanın orta kesiminde ve Yarışlı Gölü'nün batısında SLK değerleri görünürde tektonik hatlara bağlı olmadan anomali vermektedir (Şekil 7 ve 8). Her iki kesimde ofiyolitik melanj niteliğindeki kayaçlar yüzeylemektedir. $\mathrm{Bu}$ anomaliler ofiyolit içindeki blok ve matriks arasındaki litolojik farklilıktan kaynaklanmış olmalıdır. Ayrıca inceleme alanının güneyinde 9 nolu havzada ve alanın doğusunda 4 nolu havzanın üst kesimlerinde de SLK değerleri anomali vermektedir. $\mathrm{Bu}$ havzaların olduğu kesimde Burdur Formasyonu'na ait değişik özellikli litolojiler yüzeylemektedir. Formasyon içerisindeki litolojik farkl1lıklar bu anomalinin nedeni olarak görülmektedir.

Çalışma alanındaki havza ve akarsulara ait ortalama SLK değerleri en düşük 1,84 ile 24 nolu havzaya aitken en yüksek 7,95 ile 4 nolu havzada gözlenmiştir (Çizelge 2). Bunun yanısıra 15 numaralı (SLK 4,55), 1 numaralı (SLK 3,98) ve 17 numaralı (SLK 3,94) havzalardaki ortalama SLK değeri Sınıf 1 tektonik aktivitenin yüksek olduğu bölgeler için karakteristiktir. Bunun tersine 7 numaralı (SLK 2,35) 24 numaralı $(1,84)$ ve 12 nolu $(2,45)$ akarsulardaki değerler ise Sınıf 3 tektonik aktivenin düşük olduğu bölgelere özgü değerler sunmaktadır. Geri kalan diğer havzalar ise Sinıf 2 tektonik aktivitenin orta seviyede olduğu sınıfta bulunmaktadır. Buna göre ortalama SLK değerlerinin tamamı incelendiğinde çalışılan alan genel olarak orta ve yüksek tektonik aktiviteye sahiptir (Çizelge 2).

SLK değerleri analiz edildiğinde Burdur Fayı'nın yer aldığı 1.alt alanda ortalama SLK değeri 3,53, Yarışlı Gölü çevresindeki 2. alt alanda ortalama SLK değeri 3,72, Karakent Fayı'nın yer aldığ1 3. alt alanda ise ortalama SLK değeri 3,13 olarak belirlenmiştir (Çizelge 3). Bu değerlere göre Yarışlı Gölü çevresindeki 2. alt alana ait 
ortalama SLK değeri Sınıf 1 tektonik aktivitenin yüksek olduğu grupta yer almaktadır. Diğer iki alan ise Sinıf 2 tektonik aktivitenin orta seviyede olduğu bölgede bulunmaktadır (Şekil 5). Ancak ortalama SLK değerlerine bakıldığında Burdur Fayını kesen havzalardaki ortalama SLK değeri Karakent Fayı'nı kesen havzalardaki ortalama SLK değerine göre daha yüksektir.

\section{Asimetri Faktörü (Asymmetry Factor - AF)}

İnceleme alanında bulunan Burdur Gölü Havzası her iki taraftan Burdur ve Karakent fayları ile sınırlandırılmıştır. Belirlenen havzanın toplam alanı 410,525 km² iken havzanın dere akış yönünün sağında kalan alan 246,904 km² dir. Bu değerlere göre AF indisi 60,14 olarak hesaplanmıştır (Şekil 9a). AF indisinin fazla çıkması bize havzanın asimetrik bir yapısı olduğunu ve Burdur Fayı'nın olduğu kesimin Karakent Fayı'nın olduğu kesime göre daha fazla yükseldiğini göstermektedir. Havzanın her iki kesimindeki litolojik özellikler göz önüne alındığında havzanın orta kesiminde Burdur Fayı'nın olduğu bölgede kolaylıkla aşınabilir kayaçların bulunması bu asimetriyi oluşturan faktörlerden biridir. Bununla beraber havzanın KD ve GB kesiminde benzer litolojilerin olduğu alanlarda da aynı asitmetrinin gözlenmesi litolojik özelliklerin yanı sıra, tektonik olayların da bu asimetrinin oluşmasında rolü olduğu ortaya çıkmaktadır (Şekil 2 ve 9a). Buna göre havzadan elde ettiğimiz AF-50 mutlak değeri 10,14 olarak hesaplanmıştır. Bu değerde havzanın Sınıf -2 orta seviyede tektonik aktiviteye sahip ve orta derecede eğimlenmiş (tiltleşmiş) olduğunu göstermektedir.

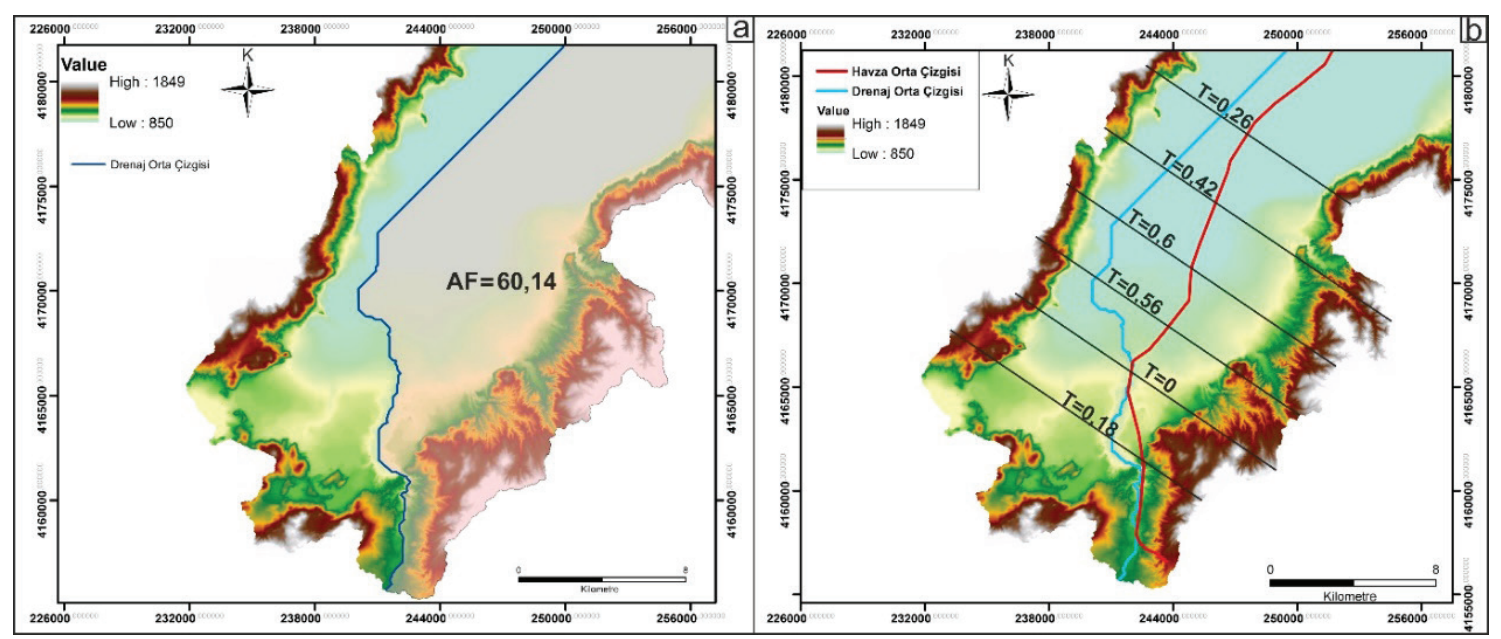

Şekil 9. a) Burdur Havzasına ait a) Asimetri Faktörü (AF) ve b) Topografi Simetri Faktörü.

Figure 9. a) Asymmetry Factor (AF) and b) Topographic Symmetry Factor (T) of the Burdur Basin. 


\section{Topografi simetri faktörü (Topographic Symmetry Factor - T)}

Havza asimetrisinde kullanılan diğer bir değer ise $\mathrm{T}$ indisidir. $\mathrm{Bu}$ indis bir havzanın hangi kısmının daha asimetrik olduğunu belirlemede kullanılır. Yapılan çalışmada elde edilen sonuçlara göre $T$ değeri 0 ile 0,6 arasında değişim göstermektedir (Şekil 9b). Değerler GB'dan KD' ya doğru sirasiyla $0,18,0,0,56,0,6,0,42,0,26$ şeklindedir. Havzanın ortasında bulunan değerler yaklaşık 0,3 ile 0,6 arasında değişirken, KD ucunda 0,2 ile 0,3 , GB ucunda ise 0 ile 0,18 arasında değişim göstermektedir. Havza ortasındaki bu asimetrinin fazla olmasinın en önemli nedenlerinden biri de havzanın her iki tarafındaki litolojik farklılıktır (Şekil 2 ve 9b).

\section{Göreceli Aktif Tektonik İndeksi (Index of Relative Active Tectonics-Iat)}

İnceleme alanındaki havza, alt alan ve faylardan hangilerinin tektonik olarak daha aktif bir yapıya sahip olduğunu belirlemek amacı ile Göreceli Aktif Tektonik İndeksi (Iat) kullanılmıştır. Havzaların indeksini belirlemek için ortalama SLK ve Vf değerleri, alt alanların değerlerini belirlemek için ortalama SLK, Vf ve Smf değerleri birlikte kullanımıştır. 27 adet havzanın Iat indeksi 1,5 ile 3 arasında değişmektedir (Şekil 5). 3 ve 27 nolu havzalara ait Iat değeri 1,5 olup Sınıf-2 yüksek derecede tektonik aktiviteye sahiptir. 1, 4, 15, 17 , nolu havzaların Iat indeksleri 2 olup Sinif-3 orta seviyede tektonik aktiviteyi göstermektedir (Şekil 5) (Çizelge 2). Diğer havzaların ise Iat değeri 2,5 ile 3 arasında değişmekte ve Sınıf-4 tektonik aktivitenin az olduğu grupta yer almaktadır. Faylar ile elde edilen değerler beraber incelendiğinde Burdur Fayı'nın KD ucunda ve Karakent Fayı'nın KD ucunda tektonik aktivite Iat değerine göre daha yüksek, Yarışlı Gölü'nün de batı ve güney kesiminin havza bazlı olarak daha aktif olduğu gözlenmektedir. Karakent Fayı boyunca litolojik özellikler farklılık göstermezken Burdur
Fayı’nın geçtiği kesimlerdeki litolojik özellikler oldukça farklılık sunmaktadır. Temel kayalarının yüzeylediği KD ucunda havza aktivitesi daha fazla iken örtü kayaçların yaygın olarak yüzeylediği orta kesimlerde bulunan havzalarda tektonik aktivite daha düşük olarak gözlenmiştir (Şekil 2 ve 5).

Ortalama Smf, Vf, SLK değerlerine göre Iat değerlerinin hesaplandiğ 1 . ve 3. alt alanlardaki Iat indeksi 2 (Sınıf-3), 2. alt alandaki Iat indeksi 1,66 (Sınıf-2) olarak elde edilmiştir (Çizelge 3). Buna göre Burdur ve Karakent faylarının yer aldığı 1 . ve 3. alt alanlarda orta derecede tektonik aktivite gözlenirken, Yarışlı Gölü etrafındaki fayları içeren 2. alt alanda yüksek derecede tektonik aktivite izlenmektedir (Çizelge 3).

\section{SONUÇLAR VE TARTIŞMALAR}

$\mathrm{Bu}$ çalışmada Fethiye Burdur Fay Zonu'nun (FBFZ) kuzeydoğu kesiminin (Burdur -Kozluca arası) tektonik aktivite ile ilişkili jeomorfolojik indisleri incelenerek elde edilen sonuçlar inceleme alanının jeolojik özellikleri (Şekil 2) ile karşılaştırılmıştır. Buna göre inceleme alanındaki dağ cephelerinden değerleri 1,03 ile 1,66 arasında değişen 21 adet Smf indisi hesaplanmıştır (Şekil 4). Faylara göre ortalaması alınan Smf değerleri Burdur Fayı'nın geçtiği yerlerde en yüksek ortalamayı $(1,27)$ vermiştir. Smf değerinin Burdur Fayı üzerinde beklenmeyen ölçüde yüksek çıkması bize litolojinin Smf değeri üzerindeki etkisini göstermektedir. Hesaplanan Smf değerlerinin sonucuna göre inceleme alanındaki Burdur, Karakent ve Yarışlı Gölü etrafındaki faylar Sınıf1 grubu içerisine düşmektedir. $\mathrm{Bu}$ da inceleme alanının, tektonik olarak yüksek derecede aktif olduğunu göstermektedir.

27 adet havzaya ilişkin ortalama Vf değeri 0,28 ile 10,85 arasında değişim göstermektedir. $\mathrm{Bu}$ da bize inceleme alanında hem " $U$ " hem de "V" şekilli vadilerin bulunduğunu gösterir. Bazı derelerde fayları kesen ve litolojik farklılığın 
olmadı̆̆ı bölgelerde "U” şekilli vadilerin "V" şekilli vadilere geçişi tektonik aktiviteye bağlıdır. Vf değerlerine göre inceleme alanı Sınıf-3 tektonik aktvitenin düşük olduğu değerler sunmaktadır. Ayrıca bu bölgede en yüksek ortalama Vf değeri 5,20 ile Burdur fayının geçtiği 1. alt alanda izlenmektedir. Diğer alt alanlara göre bu değerin daha yüksek olması büyük olasılıkla litolojik faktörle ilişkilidir.

İnceleme alanındaki havzalara ilişkin ortalama SLK değerleri 1,84 ile 7,95 arasında değişim sunmaktadır. Havzalara ilişkin ortalama SLK değerlerinin tamamı incelendiğinde inceleme alanı genel olarak orta ve yüksek tektonik aktiviteye sahiptir. Bununla beraber alt alanlardaki ortalama SLK değerleri, Yarışlı Gölü çevresinin Sınıf-1 tektonik aktivitenin yüksek olduğu, diğer 2 alt alan ise Sınıf-2 tektonik aktivitenin orta seviyede olduğu grupta yer aldığını göstermektedir. Yine ortalama SLK değerlerine bakıldığında Burdur Fayı'nın bulunduğu havzalardaki ortalama SLK değeri (3,53) Karakent Fayı'nın bulunduğu havzalardaki ortalama SLK değerine $(3,13)$ göre daha yüksektir. Bu da bize Burdur Fayı'nın Karakent Fayı'na göre tektonik aktivitesinin daha fazla olduğunu göstermektedir.

Asimetri Faktörü $\quad(\mathrm{AF}=60,14) \quad$ Burdur Havzası'nın GD'sunu oluşturan ve Burdur Fayı'nın geçtiği kesimin Karakent Fayı'nın geçtiği KB kesimine göre daha fazla yükseldiğini dolayısıyla eğimlenmenin KB'ya doğru olduğunu belirtmektedir. Dolayısıyla BurdurFayı'nın olduğu kesimin tektonik aktivitesi daha fazla olmalıdır. Havzadan elde ettiğimiz AF-50 mutlak değeri 10,14 olarak hesaplanmıştır. Bu değer de havzanın Sınıf -2 orta derecede eğimlenmiş (tiltleşmiş) ve orta seviyede tektonik aktiviteye sahip bir havza olduğunu kanıtlamaktadır. Topoğrafi simetri değerleri havzanın uzun ekseni boyunca 0 - 0,6 arasında değişmektedir. Havzanın ortasındaki değerlerin $(0,3-0,6), \mathrm{KD}(0,2-0,3)$ ve GB $(0-0,18)$ kesimlerine göre daha yüksek olmasının en önemli nedenlerinden biri de havzanın her iki tarafindaki litolojik farkl11ıktır (Şekil 9b). Bununla beraber asimetri değerleri göz önüne alındığında havzanın orta kesiminin diğer kesimlere göre daha aktif bir yapıya sahip olduğu gözlenmektedir. Aletsel dönemdeki deprem episantır dağılımları da benzer bir sonuç vermektedir (Şekil 2).

İnceleme alanındaki 27 adet havzanın Iat değeri 1,5 ile 3 arasında değişmektedir. Sadece ortalama SLK ve Vf değerlerinin kullanıldığ Iat değerlerinin bir kısmı Sınıf-2 tektonik aktivitenin yüksek olduğu, bir kısmı Sınıf-3 tektonik aktivitenin orta seviyede olduğu, çoğunluğu ise Sınıf-4 tektonik aktivitenin düşük olduğu alana düşmektedir. Ortalama Smf, Vf ve SLK değerlerinin yer aldığı Iat değerlerine göre ise 2. alt alan $(1,66)$ Sinıf-2 tektonik aktivitenin yüksek olduğu, 1. ve 3. alt alanlar (2) ise Sınıf-3 tektonik aktivitenin orta seviyede olduğu grupta bulunmaktadır (Çizelge 3).

Sonuç olarak jeomorfolojik indislerden elde ettiğimiz veriler Burdur, Karakent, Karacaören ve Karaçal faylarının yer aldı ̆̆ inceleme alanının orta ve yüksek dereceli tektonik aktiviteye sahip olduğunu göstermektedir.

\section{EXTENDED SUMMARY}

The aim of this study is to investigate the relative tectonic activity of NE side of Fethiye Burdur Fault Zone (South Burdur) by using the geomorphological indices and interpret them with the geological features of the area. The FethiyeBurdur Fault Zone (FBFZ) in the south-western Anatolia is aproximately $300 \mathrm{~km}$ long and 15 $90 \mathrm{~km}$ in width and is left lateral oblique-slip normal fault zone (Figure 1a) (Dumont et al., 1979; Yağmurlu, 2000; Elitez and Yaltırak, 2014; Hall et al., 2014). The NE-SW trending FBFZ is extending from the Fethiye bay in the southwest to the Çay-Afyon region in the north east (Figure 1b). In the study area the northeast part of the FBFZ is characterized by NE-SW trending Burdur, 
Karakent, Karacaören faults and NW-SE trending Karaçal fault (Şaroğlu et al., 1987; Yağmurlu et al., 2005; Bozcu et al., 2007; Emre et al., 2011; Aksarl, 2016; Coşkuner, 2017) (Figure 2). Also the region contains lots of small scale faults. The stratigraphic and lithological units that crop out in study area range from Triassic to Holocene in age. The Upper Triassic-Lower Jurassic Taşkesiği formation and Upper Cretaceous Kizllcadağ ophiolitic melange form the base units of the area (Poisson, 1977; Şenel et al., 1989; Şenel ve Bölükbaşl, 1997; Moix et al., 2013; Coşkuner, 2017). Neogene-Quaternary lacustrine, fluvial and alluvial deposits unconformably overlie the basement units (Karaman, 1986; Bozcu et al., 2007; Aksoy and Aksarl 2016; Coşkuner, 2017; Coşkuner and Aksoy, 2017) (Figure 2). The region is seismically active and has also experienced many destructive earthquakes during historical and instrumental periods.

In order to determine the tectonic activity of the region by geomorphological indices, firstly, we used Arc GIS 10.0 software to create 10 m resolution Digital Elevation Model (DEM) from 1/25000 scale topographic maps. We used ArcHydro Tools in ArcGIS to extract in total 27 drainage basins and stream trunks from the DEM. Then MountainFront Sinuosity (Smf), Ratio of Valley-Floor Width to Valley Height (Vf), Normalized Stream Length - Gradient Index (SLK), Asymmetry Factor (AF) and Topographic Symmetry Factor (T), were calculated (Figure 3). Finally, Index of relative active tectonics (Iat) was extracted from the some indices for the individual basins and three subareas that are divided into according to the main faults. The results were elucidated and compared with the lithological and structural variations of the area using the appropriate classifications given by (Bagha et al., 2014; Bull and Mcfadden, 1977; Chen et al., 2003; Cheng et al., 2018; Dehbozorgi et al., 2010; El Hamdouni et al., 2008; Gao et al., 2013; Köle, 2016; Pérez-Peña et al., 2009; Selim et al., 2013; Silva et al., 2003; Xue et al., 2017).
In this study Smf (Mountain-Front Sinuosity) values computed for twenty one fronts (Figure 4). The results are shown in Table 1. Amongs them the highest Smf value is 1.66 and calculated on the Burdur fault. The lowest Smf value is 1.03 and is obtained from a branch of the Burdur Fault. The calculated mean Smf values show that the highest value belongs to the fronts paralel to the Burdur fault. This result is contrast to the very high tectonic activity of the fault. Most probably this situation is resulted from the wide spread occurence of loose textured and easily erodible rocks around the Burdur fault.

Vf (Ratio of Valley-Floor Width to Valley Height) values were estimated from 27 main channel and from 2 branches that cut the faults (Figure 4). The calculated mean Vf values in the study area vary between 0.28-10.85 (Table 2), and demonstrate that the existence of both " $U$ " and " $V$ " shaped valleys through the streams. The variations of Vf values, show transition from the " $U$ " to the " $V$ " shapes in some localities of 5-7-1415-16 and 18 numbered valleys (Figure 5). There is no lithological differences through the 15-16 main channels and these transitions are thought to be caused mainly by tectonic movements.

The SL (Stream Length - Gradient Index) indexes, were calculated for 27 main streams and their profiles have been drawn in Figure 6. When the profiles were examined in detail, it was observed that the SL values give anomalies where there are sudden changes in slope of streams (1-2-7a-11-1415-1 and 18). In order to compare the SL values more accurately for the streams of the different lengths, the normalization factor $(K)$ of each stream was calculated and SLK (Normalized Stream Length - Gradient Index) values were computed as can be seen in Figure 7. The average SLK value is classified for the three sub-areas, and it is observed that the highest mean SLK value belongs to the subarea of Yarlşl Lake. The contoured map of the SLK values mainly give prominent anomalies paralel to the faults (Figure 8). 
Asymmetry Factor (AF) is used to calculate the asymmetry of a basin which is a consequences of lithological differences or tectonic activities. Northeast - Southwest trending Burdur basin is surrounded by Burdur to the southeast and Karakent faults to the northwest in the study area. We applied AF for finding out the relative differences of activity of these faults. According to our calculations, AF index is 60.14 (Figure 9a). This numerical value showed that the basin has an asymmetrical structure and is tilted to the northwest. This situation is resulted from more tectonic activity of Burdur fault than the Karakent fault. The Topography Symmetry Factor (T) in literature, was generally used to determine which part of the basin is more asymmetric than the other parts. The T value varies between 0 and 0,6 along the basin and is more higher in the middle part than the northeast and southwest parts (Figure 9b). From this it can be said that the tectonic activity in the central part of the basin is more than the other sides.

The Relative Active Tectonic Index (Iat) was generally used to compare tectonic activity differences of the basins and the faults (El Hamdouni et al., 2008; Cheng et al., 2018). In order to determine the Iat-index, mean SLK, $V f$ and Smf values were combined for the three sub-areas, and mean SLK and Vf used for the 27 basins (Table 3). The Iat index of the basins vary between 1,5-3. Some basins have Iat index representing Class 2 and 3 (high and moderate tectonic activity), but the general Iat index point out Class 4 (low tectonic activity). The first subarea has Class 2-High tectonic activity. The Iat index of second and third sub areas fall into the Class-3 and exhibit moderate tectonic activity (Table 3).

As a result, the data obtained from the geomorphic indices show that the studied area has moderate to high level tectonic activity.

\section{ORCID}

Berkant COŞKUNER (D) https://orcid.org/0000-0002-9798-8793

Yaşar EREN D https://orcid.org/0000-0002-7899-8507

Ramazan DEMIRCIOĞLU (D) https://orcid.org/0000-0003-0616-0331

Rahmi AKSOY (D) https://orcid.org/0000-0002-9199-7410

\section{DEĞINILEN BELGELER / REFERENCES}

Aksarı, S., 2016. Burdur - Fethiye Fay Zonunun Kemer (Burdur) - Çameli (Denizli) arasındaki bölümünün yapısal evrimi. Doktora Tezi, Selçuk Üniversitesi Fen Bilimleri Enstitüsü, Konya, 194 s., (yayımlanmamış).

Aksoy, R. ve Aksarı, S., 2016. Neogene-Quaternary evolution of the Tefenni basin on the FethiyeBurdur fault zone, SW Anatolia-Turkey. Journal of African Earth Sciences, 118, 137-148.

Alçiçek, M.C., 2001. Sedimentological Investigation of Çameli Basin (Late Miocene - Late Pliocene, Denizli, (SW Anatolia). Doktora Tezi, Ankara Üniversitesi Fen Bilimleri Enstitüsü, Ankara, 110 s., (yayımlanmamış).

Alçiçek, M. C., Mayda, S. ve Titov, V. V., 2013. Lower Pleistocene stratigraphy of the Burdur basin of SW Anatolia. Comptes Rendus Palevol, 12, 1-11.

Alçiçek, M.C., 2015. Comment on "The FethiyeBurdur Fault Zone: A component of upper plate extension of the subduction transform edge propagator fault linking Hellenic and Cyprus Arcs, Eastern Mediterranean. Tectonophysics 635, 80-99" by J. Hall, A.E. Aksu, İ. Elitez, C. Yaltırak, G. Çiftçi. Tectonophysics, 664, 1-4.

Angelier, J., Dumont, J., Karamanderesi, H., Poisson, A., Şimşek, Ş. ve Uysal, Ş., 1981. Analyses of fault mechanisms and expansion of southwestern Anatolia since the late Miocene. Tectonophysics, 75 (3.), 1-9.

Azor, A., Keller, E. A. ve Yeats, R. S., 2002. Geomorphic indicators of active fold growth: South Mountain-Oak Ridge anticline, Ventura basin, southern California. Geological Society of America Bulletin, 114 (6), 745-753.

Bagha, N., Arian, M., Ghorashi, M., Pourkermani, M., El Hamdouni, R. ve Solgi, A., 2014. Evaluation of relative tectonic activity in the Tehran basin, 
central Alborz, northern Iran. Geomorphology, 213, 66-87.

Barka, A. ve Reilinger, R., 1997. Active tectonics of the Eastern Mediterranean region: deduced from GPS, neotectonic and seismicity data. Annals of Geophysics, 40 (3), 587-610.

Barka, A., Reilinger, R., Şaroğlu, F. ve Şengör, A., 1995. The Isparta Angle: its importance in the neotectonics of the Eastern Mediterranean Region. International Earth Sciences Colloqium on the Aegean Region, 1, 3-17.

Boğaziçi Üniversitesi Kandilli Rasathanesi ve Deprem Araştırma Enstitüsü, 2019. www.koeri.boun.edu. tr, 22 Mart 2019.

Bozcu, M., Yağmurlu, F. ve Şentürk, M., 2007. FethiyeBurdur Fay Zonunun Bazı Neotektonik ve Paleosismolojik Özellikleri, GB-Türkiye. Jeoloji Mühendisliği Dergisi, 31 (1), 25-48.

Bozkurt, E., 2001. Neotectonics of Turkey-a synthesis. Geodinamica Acta, 14 (1-3), 3-30.

Brookfield, M., 1998. The evolution of the great river systems of southern Asia during the Cenozoic India-Asia collision: rivers draining southwards. Geomorphology, 22 (3-4), 285-312.

Bull, W.B., 1978. Geomorphic Tectonic class of the South Front of the San Gabriel Mountains, California. U.S. Geological Survey, Contract Report, 14-08-001-G-394.

Bull, W.B. ve McFadden, L.D., 1977. Tectonic Geomorphology North and South of the Garlock Fault, California. Geomorphology in Arid Regions. 8th Annual Geomorphology Symposium, University of New York, 23-24 September 1977, D.O. Doehring (ed.), Binghamton, 115-138.

Chen, Y. C., Sung, Q. ve Cheng, K. Y., 2003. Alongstrike variations of morphotectonic features in the Western Foothills of Taiwan: tectonic implications based on stream-gradient and hypsometric analysis. Geomorphology, 56 (1-2), 109-137.

Cheng, Y., He, C., Rao, G., Yan, B., Lin, A., Hu, J., Yu, Y. ve Yao, Q., 2018. Geomorphological and structural characterization of the southern Weihe Graben, central China: Implications for fault segmentation. Tectonophysics, 722, 11-24.

Cohen, H., Dart, C., Akyüz, H. ve Barka, A., 1995. Syn-rift sedimentation and structural development of the Gediz and Büyük Menderes graben, western Turkey. Journal of the Geological Society, 152 (4), 629-638.

Coşkuner, B., 2017. Fethiye - Burdur Fay Zonunun Kozluca - Burdur Arasındaki Bölümünün Neotektonik Özellikleri, GB Anadolu, Türkiye. Yüksek Lisans Tezi, Selçuk Üniversitesi Fen Bilimleri Enstitüsü, Konya, 80 s., (yayımlanmamış).

Coşkuner, B., ve Aksoy, R., 2017. Kinematic and Structural Characteristics Of The Fethiye-Burdur Fault Zone Between Boğaziçi and Çendik (Burdur), SW Anatolia, Turkey. Internatıonal Symposium On GIS Applications In Geography \& Geosciences, Çanakkale, s.:81.

Cox, R. T., 1994. Analysis of drainage-basin symmetry as a rapid technique to identify areas of possible Quaternary tilt-block tectonics: An example from the Mississippi Embayment. Geological Society of America Bulletin, 106 (5), 571-581.

Dehbozorgi, M., Pourkermani, M., Arian, M., Matkan, A., Motamedi, H. ve Hosseiniasl, A., 2010. Quantitative analysis of relative tectonic activity in the Sarvestan area, central Zagros, Iran. Geomorphology, 121 (3-4), 329-341.

Dilts, T. E., 2015. Polygon to Centerline Tool for ArcGIS. University of Nevada Reno. Available at: http://www.arcgis.com/home/item.html?id=bc642 731870740aabf48134f90aa6165

Dumont, J., Poisson, A. ve Şahinci, A., 1979. Sur l'existence de coulissements sinistres recentes a l'extermité orientale de l'arc ageen (sud-ouest de la Turquie). Comptes Rendus Acadademie Science Paris, 289, 261-264.

Duvall, A., Kirby, E. ve Burbank, D., 2004. Tectonic and lithologic controls on bedrock channel profiles and processes in costal California. Journal of Geophysical Research, 109 (F3).

Elitez, İ. ve Yaltırak, C., 2014. Çameli Havzası'nın Miyosen-Kuvaterner Jeodinamiği, Burdur-Fethiye Makaslama Zonu (GB Türkiye). Türkiye Jeoloji Bülteni, 57 (3), 41-67.

Elitez, İ., Yaltırak, C., Hall, J., Aksu, A.E. ve Çifçi, G., 2015. Reply to the comment by M.C. Alçiçek on "The Fethiye-Burdur Fault Zone: A component of upper plate extension of the subduction transform 
edge propagator fault linking Hellenic and Cyprus Arcs, Eastern Mediterranean," Tectonophysics, 635, 80-99, by J. Hall, A.E. Aksu, İ. Elitez, C. Yaltirak and G. Çifçi. Tectonophysics, 664, 5-13.

Elitez, İ., Yaltırak, C. ve Aktuğ, B., 2016. Extensional and compressional regime driven left-lateral shear in southwestern Anatolia (eastern Mediterranean): The Burdur-Fethiye Shear Zone. Tectonophysics, 688, 26-35.

Elitez, İ., Yaltırak, C., Kürçer, A., Özdemir, E. ve Güldoğan, Ç. U., 2017. A critical review of the Kibyra Fault (Burdur-Fethiye Shear Zone, SW Turkey). Geodinamica Acta, 29(1), 91-102.

El Hamdouni, R., Irigaray, C., Fernández, T., Chacón, J. ve Keller, E., 2008. Assessment of relative active tectonics, southwest border of the Sierra Nevada (southern Spain). Geomorphology, 96 (1-2), 150173.

Emre, Ö., Duman, T.Y., Özalp, S. ve Elmac1, H., 2011. 1:250.000 ölçekli Türkiye diri fay haritası serisi, Isparta Paftası. Maden Tetkik ve Arama Genel Müdürlüğü, Ankara, Türkiye. Seri No: 17.

Erakman, B., Meşhur, M., Gül, M., Alkan, H., Öztaş, Y. ve Akpınar, M., 1982. Fethiye-Köyceğiz-TefenniElmalı-Kalkan arasında kalan alanın jeolojisi, Türkiye, 6. Petrol Kongresi, Ankara, 23-31.

Eyidoğan, H. ve Barka, A., 1996. The 1 October 1995 Dinar earthquake, SW Turkey. Terra Nova, 8 (5), 479-485.

Font, M., Amorese, D. ve Lagarde, J. L., 2010. DEM and GIS analysis of the stream gradient index to evaluate effects of tectonics: the Normandy intraplate area (NW France). Geomorphology, 119 (3-4), 172-180.

Gao, M., Zeilinger, G., Xu, X., Wang, Q. ve Hao, M., 2013. DEM and GIS analysis of geomorphic indices for evaluating recent uplift of the northeastern margin of the Tibetan Plateau, China. Geomorphology, 190, 61-72.

Graciansky, P. C., 1972. Recherches géologiques dans le Taurus Lycien. Doktora Tezi, Universite de Paris-Sud, Centre d'Orsay, Paris, $731 \mathrm{~s}$.

Gürbüz, E., Kazanc1, N. ve Gürbüz, A., 2015. Strikeslip faulting, topographic growth and block movements as deduced from drainage anomalies: the Yeşilırmak River basin, northern Turkey. Geomorphology, 246, 634-648.
Hack, J. T., 1973. Stream-profile analysis and streamgradient index. Journal of Research of the US Geological Survey, 1 (4), 421-429.

Hall, J., Aksu, A., Yaltırak, C. ve Winsor, J., 2009. Structural architecture of the Rhodes Basin: a deep depocentre that evolved since the Pliocene at the junction of Hellenic and Cyprus Arcs, eastern Mediterranean. Marine Geology, 258 (1), 1-23.

Hall, J., Aksu, A., Elitez, I., Yaltırak, C. ve Çifçi, G., 2014. The Fethiye-Burdur Fault Zone: A component of upper plate extension of the subduction transform edge propagator fault linking Hellenic and Cyprus Arcs, Eastern Mediterranean. Tectonophysics, 635, 80-99.

Hare, P. W. ve Gardner, T. W., 1985. Geomorphic indicators of vertical neotectonism along converging plate margins, Nicoya Peninsula, Costa Rica. Tectonic Geomorphology, 4, 75-104.

Jackson, J. ve McKenzie, D., 1988. Rates of active deformation in the Aegean Sea and surrounding regions. Basin Research, 1 (3), 121-128.

Karaman, M., 1986. Burdur dolayının genel stratigrafisi. Akdeniz Üniversitesi Isparta Mühendislik Fakültesi Dergisi, 2, 23-35.

Karaman, M., 1994. Isparta-Burdur arasının jeolojisi ve tektonik özellikleri. Türkiye Jeoloji Bülteni, 37 (2), 119-134.

Kaymakci, N., Özacar, A.A., Özkaptan, M., Koç, A., Gülyüz, E., Lefebvre, C., Uzel, B., Langereis, C.G. ve Sözbilir, H., 2014. Fethiye-Burdur fault zone: a myth. In: The 8th International Symposium on Eastern Mediterranean Geology (ISEMG-8), Muğla.

Kaymakci, N., Langereis, C., Özkaptan, M., Özacar, A.A., Gülyüz, E., Uzel, B. ve Sözbilir, H., 2017. Fethiye-Burdur Fault Zone (SW Turkey): a myth? In: 19th EGU General Assembly, EGU2017. COPERNICUS, Vienna, Austria, 5443.

Kaymakci, N., Langereis, C., Özkaptan, M., Özacar, A.A., Gülyüz, E., Uzel, B. ve Sözbilir, H., 2018. Paleomagnetic evidence for upper plate response to a STEP fault, SW Anatolia. Earth and Planetary Science Letters, 498, 101-115.

Keller, E.A., 1986. Investigation of active tectonics: use of surficial earth processes. Active Tectonics, Studies in Geophysics. National Academy Press, Washington, DC, 136-147 s. 
Keller, E.A. ve Pinter, N., 2002. Active Tectonics: Earthquakes, Uplift, and Landscape, Prentice Hall, Upper Saddle River, New Jersey, 362 s.

Kirby, E. ve K.X. Whipple., 2012. Expression of active tectonics in erosional landscapes. Journal of Structural Geology, 44, 54-75.

Kissel, C., Laj, C. ve Müller, C., 1985. Tertiary geodynamical evolution of northwestern Greece: paleomagnetic results. Earth and Planetary Science Letters, 72 (2-3), 190-204.

Koçyiğit, A., 1984. Güneybatı Türkiye ve yakın dolayında levha içi yeni tektonik gelişim. Türkiye Jeoloji Kurumu Bülteni, 27 (1), 1-16.

Koçyiğit, A. ve Özacar, A. A., 2003. Extensional neotectonic regime through the NE edge of the outer Isparta Angle, SW Turkey: new field and seismic data. Turkish Journal of Earth Sciences, 12 (1), 67-90.

Köle, M. M., 2016. Devrez Çayı Vadisinin Tektonik Özelliklerinin Morfometrik İndisler ile Araştırılması. Coğrafya Dergisi, 33, 20-36.

Mahmood, S. A. ve Gloaguen, R., 2012. Appraisal of active tectonics in Hindu Kush: Insights from DEM derived geomorphic indices and drainage analysis. Geoscience Frontiers, 3 (4), 407-428.

Moix, P., Vachard, D., Jamesallibon, R., Wernli, R., Kozur, H. ve Stampfli, G., 2013. Palaeotethyan, Neotethyan and hulu - pindos seriesin the lycian nappes (SW Turkey) Geodynamica implications, The Triassic System. New Developments in Stratigraphy and Paleontology Bulletin, 61, 401404.

Molin, P., Pazzaglia, F.J. ve Dramis, F., 2004. Geomorphic expression of active tectonics in a rapidly-deforming forearc, Sila massif, Calabria, southern Italy. American Journal of Science, 304 (7), 559-589.

Ntokos, D., Lykoudi, E. ve Rondoyanni, T., 2016. Geomorphic analysis in areas of low-rate neotectonic deformation: South Epirus (Greece) as a case study. Geomorphology, 263, 156-169.

Özkaptan, M., Koç, A., Lefebvre, C., Gülyüz, E., Uzel, B., Kaymakci, N., Langereis, C.G., Özacar, A.A.ve Sözbilir, H., 2014. Kinematics of SW Anatolia implications on crustal deformation above slab tear. In: EGU General Assembly Conference Abstracts, 6061.
Özkaptan, M., Kaymakcı, N., Langereis, C.G., Gülyüz, E., Özacar, A.A., Uzel, B. ve Sözbilir, H., 2018, Age and kinematics of the Burdur basin: Inferences for the existence of the Fethiye-Burdur Fault Zone in SW Anatolia (Turkey). Tectonophysics, 744, 256-274.

Özkaymak, Ç., 2015. Tectonic analysis of the Honaz Fault (western Anatolia) using geomorphic indices and the regional implications. Geodinamica Acta, 27 (2-3), 110-129.

Pérez-Peña, J., Azañón, J., Azor, A., Delgado, J. ve González-Lodeiro, F., 2009, "Spatial analysis of stream power using GIS: SLk anomaly maps". Earth Surface Processes and Landforms, 34 (1), 16-25.

Price, S., 1989. Sedimentation and Neotectonic of the Burdur Region, SW Turkey. Doktora Tezi, University of Leicester, Leicester.

Poisson, A., 1977. Recherches géologiques dans les Taurides occidentales (Turquie). Doktora Tezi, Universite de Paris-Sud., Centre D’Orsay.

Ramírez-Herrera, M.T., 1998. Geomorphic assessment of active tectonics in the Acambay Graben, Mexican volcanic belt. Earth Surface Processes and Landforms, 23, 317-332.

Sarp, G. ve Düzgün, Ş., 2012. Spatial analysis of morphometric indices: the case of Bolu pull-apart basin, western section of North Anatolian Fault System, Turkey. Geodinamica Acta, 25 (1-2), 8695.

Seeber, L. ve Gornitz, V., 1983. River profiles along the Himalayan arc as indicators of active tectonics. Tectonophysics, 92 (4), 335-367.

Selim, H., Tüysüz, O., Karakaş, A. ve Taş, K., 2013. Morphotectonic evidence from the southern branch of the North Anatolian Fault (NAF) and basins of the south Marmara sub-region, NW Turkey. Quaternary international, 292, 176-192.

Seyitoğlu, G. ve Scott, B., 1991. Late Cenozoic crustal extension and basin formation in west Turkey. Geological Magazine, 128 (02), 155-166.

Silva, P. G., Goy, J., Zazo, C. ve Bardaj1, T., 2003. Fault-generated mountain fronts in southeast Spain: geomorphologic assessment of tectonic and seismic activity. Geomorphology, 50 (1-3), 203-225. 
Şaroğlu, F., Emre, Ö. ve Boray, A., 1987. Türkiye'nin diri fayları ve depremsellikleri. MTA Rapor No 394.

Şenel, M., Selçuk, H., Bilgin, Z., Şen, A., Karaman, T., Dinçer, M. ve Bilgi, C., 1989. Çameli (Denizli)Yeşilova (Burdur)-Elmalı (Antalya) ve Dolayının Jeolojisi. MTA Raporu, 9429.

Şenel, M. ve Bölükbaş1, A., 1997. Geological Map of Fethiye, M9 quadrangle, No: 5, 1: 100,000, General Directorate of Mineral Research and Exploration, Ankara, Turkey.

Şengör, A. M. C., 1987. Cross-faults and differential stretching of hanging walls in regions of low-angle normal faulting: examples from western Turkey. Geological Society London Special Publications, 28 (1), 575-589.

Taymaz, T. ve Price, S., 1992. The 1971 May 12 Burdur earthquake sequence, SW Turkey: a synthesis of seismological and geological observations. Geophysical Journal International, 108 (2), 589603.

Ten Veen, J. H., 2004. Extension of Hellenic forearc shear zones in SW Turkey: the PlioceneQuaternary deformation of the Eşen Çay Basin. Journal of Geodynamics, 37 (2), 181-204.

U. S. Geological Survey, 2019. www.usgs.gov, 22 March 2019.

VanLaningham, S., Meigs, A. ve Goldfinger, C., 2006. The effects of rock uplift and rock resistance on river morphology in a subduction zone forearc, Oregon, USA. Earth Surface Processes and Landforms, 31 (10), 1257-1279.

Whipple, K.X., 2004. Bedrock rivers and the geomorphology of active orogens. Annual Review of Earth and Planetary Sciences, 32, 151-185.

Wu, L., Xiao, A., ve Yang, S., 2014. Impact of wind erosion on detecting active tectonics from geomorphic indexes in extremely arid areas: a case study from the Hero Range, Qaidam Basin, NW China. Geomorphology, 224, 39-54.
Xue, L., Gani, N. D. ve Abdelsalam, M. G., 2017. Geomorphologic proxies for bedrock rivers: A case study from the Rwenzori Mountains, East African Rift system. Geomorphology, 285, 374398.

Yağmurlu, F., Savaşçın, Y. ve Ergün, M., 1997. Relation of alkaline volcanism and active tectonism within the evolution of the Isparta Angle, SW Turkey. The journal of geology, 105 (6), 717-728.

Yağmurlu, F., 2000. Burdur fayının sismotektonik özellikleri. Batı Anadolunun Depremselliği Sempozyumu, 24-27 Mayıs 2000, İzmir, 143-151.

Yağmurlu, F., Bozcu, M. ve Şentürk, M., 2005. BurdurFethiye Arasındaki Bölgede Burdur Fayının Sismotektonik Özellikleri. TÜBİTAK, Proje No: $101 \mathrm{Y} 027,79 \mathrm{~s}$.

Yaltırak, C., İşler, E.B., Aksu, A.E. ve Hiscott, R.N., 2012. Evolution of the Bababurnu Basin and shelf of the Biga Peninsula: western extension of the middle strand of the North Anatolian Fault Zone, Northeast Aegean Sea. Turkey. Journal of Asian Earth Sciences, 57, 103-119.

Yazıc1, M., Zabcı, C., Sançar, T. ve Natalin, B.A., 2018. The role of intraplate strike-slip faults in shaping the surrounding morphology: The Ovacik Fault (eastern Turkey) as a case study. Geomorphology, 321, 129-145.

Yıldırım, C., 2014. Relative tectonic activity assessment of the Tuz Gölü fault zone; Central Anatolia, Turkey. Tectonophysics, 630, 183-192.

Zanchi, A., Kissel, C. ve Tapırdamaz, C., 1993. Late Cenozoic and Quaternary brittle continental deformation in western Turkey. Bulletin de la Société Géologique de France, 164 (4), 507-517. 
